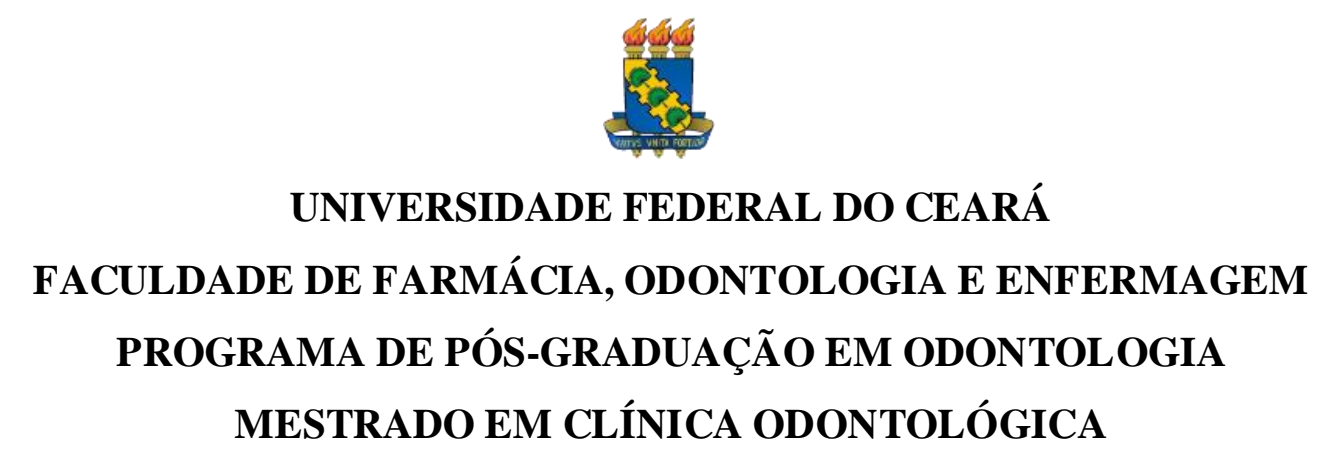

STHEFANE GOMES FEITOSA

AVALIAÇÃO DA IMUNOEXPRESSÃO DE PI3K E PTEN EM CERATOCISTOS ODONTOGÊNICOS E AMELOBLASTOMAS

FORTALEZA 


\section{AVALIAÇÃO DA IMUNOEXPRESSÃO DE PI3K E PTEN EM CERATOCISTOS ODONTOGÊNICOS E AMELOBLASTOMAS}

Dissertação apresentada ao Programa de PósGraduação em Odontologia da Faculdade de Farmácia, Odontologia e Enfermagem da Universidade Federal do Ceará, como um dos requisitos para obtenção do título de Mestre em Odontologia.

Orientadora: Profa. Dra. Karuza Maria Alves Pereira

Área de Concentração: Clínica Odontológica 
Dados Internacionais de Catalogação na Publicação Universidade Federal do Ceará

Biblioteca Universitária

Gerada automaticamente pelo módulo Catalog, mediante os dados fornecidos pelo(a) autor(a)

F336a Feitosa, Sthefane Gomes.

Avaliação da imunoexpressão de PI3K e PTEN em ceratocistos odontogênicos e ameloblastomas /

Sthefane Gomes Feitosa. - 2018.

$66 \mathrm{f}$ : : il. color.

Dissertação (mestrado) - Universidade Federal do Ceará, Faculdade de Farmácia, Odontologia e

Enfermagem, Programa de Pós-Graduação em Odontologia, Fortaleza, 2018.

Orientação: Profa. Dra. Karuza Maria Alves Pereira.

1. Ameloblastoma. 2. Ceratocisto odontogênico. 3. Imunohistoquímica. 4. PI3K. 5. PTEN. I. Título.

CDD 617.6 
STHEFANE GOMES FEITOSA

\section{AVALIAÇÃO DA IMUNOEXPRESSÃO DE PI3K E PTEN EM CERATOCISTOS ODONTOGÊNICOS E AMELOBLASTOMAS}

Dissertação de Mestrado submetida à Coordenação do Programa de Pós-Graduação em Odontologia, da Universidade Federal do Ceará, como requisito para a obtenção do título de Mestre em Odontologia; Área de Concentração: Clínica Odontológica.

Aprovada em:<smiles>C1CC(C2CC2)C1</smiles>

BANCA EXAMINADORA

Prof. Dra. Karuza Maria Alves Pereira (Orientadora) Universidade Federal do Ceará - UFC

Prof. Dra. Malena Regina de Freitas e Silva Centro Universitário Christus - UNICHRISTUS

Prof. Dr. Paulo Goberlânio de Barros Silva Universidade Federal do Ceará - UFC 


\section{AGRADECIMENTOS}

Agradeço a Deus pelo dom da vida, pelo fortalecimento do espírito e pela luz nos caminhos de dificuldade.

Aos meus pais, Liliane e Silvio (in memorian), minha fonte de inspiração, ensinandome sempre a agir com ética, verdade e a lutar pelos meus sonhos.

Ao meu esposo, Denis Oliveira, por todos os momentos vivenciados, pela paciência em me ouvir, pelos valores repassados, pela motivação em busca da superação em todas as situações e por me revelar a cada dia o verdadeiro sentido da vida.

A minha orientadora Profa. Dra. Karuza Maria Alves Pereira pelos ensinamentos acadêmicos, pela contribuição na minha formação pessoal e profissional e por transmitir tão grandiosamente o valor da docência e da pesquisa.

Aos professores Mário Rogério Lima Mota, Ana Paula Negreiros Nunes Alves, Paula Goes Pinheiro Dutra, Ana Karine Macedo Teixeira e Delane Viana Gondim pelos brilhantes ensinamentos e pela inspiração que representam como mestres.

Aos amigos Thâmara Marinho, Filipe Nobre, Ealber Luna, Thaís Torres, Paulo Goberlânio, Alceu Machado, Débora Rejane Alves, Thalyta Amanda, Mariana Canuto, Karine Cestaro, Thinali Dantas, Elisa Quezado por todo apoio durante as pesquisas e pelo compartilhamento de relevantes momentos na pós-graduação.

À instituição Universidade Federal do Ceará, em nome do reitor Henry de Holanda Campos.

Aos coordenadores do Programa de Pós-Graduação em Odontologia da Faculdade de Farmácia, Odontologia e Enfermagem (PPGO/UFC) Prof. Dr. Vicente De Paulo Aragão Sabóia e Prof. Dr. Fábio Wildson Gurgel Costa.

À Coordenação de Aperfeiçoamento de Nível Superior (CAPES), pela concessão da bolsa de mestrado. 


\section{RESUMO}

Os cistos odontogênicos são lesões relativamente comuns que causam destruição óssea nos maxilares. São classificados conforme sua origem em: cistos de desenvolvimento, incluindo o ceratocisto odontogênico (OKC), ou em cistos inflamatórios. Já os tumores odontogênicos correspondem a um grupo complexo de lesões de diversos tipos histopatológicos e comportamentos clínicos, sendo classificados conforme sua origem. Dentre os tumores de origem epitelial odontogênica, o ameloblastoma (AM) é um tumor frequentemente significativo, devido ao seu crescimento lento e sua característica clínica de invasividade local. A patogênese dos cistos e tumores odontogênicos ainda é pouco elucidada e estudos buscam identificar mecanismos e vias envolvidas na formação e progressão dessas lesões. Nesse contexto, a via PI3K/AKT/PTEN tem sido analisada em algumas lesões odontogênicas, buscando compreender mecanismos envolvidos nestas. Assim, o presente estudo objetivou analisar a expressão imunohistoquímica de PI3K e PTEN em OKC e AM. A amostra foi constituída por $10 \mathrm{OKC}$ e $10 \mathrm{AM}$. A verificação imunohistoquímica foi realizada utilizando anti-PI3K (1:400) e anti-PTEN (1:400). Foram expressas as médias \pm EPM das contagens das células e dos histoscores calculados, os quais foram analisados pelo teste de Mann-Whitney, seguido do pós-teste de Dunn e correlacionados usando a correlação de Spearman. Os dados categóricos foram expressos em frequência absoluta e comparados pelo teste Exato de Fisher ou Qui-quadrado de Pearson. A análise imunohistoquímica evidenciou imunomarcação positiva em todos os casos da amostra. $\mathrm{O}$ total de células com marcação nuclear para PTEN

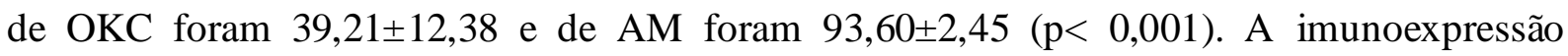
citoplasmática de PTEN para OKC foram de 87,35 $\pm 5,72$ células imunomarcadas e de

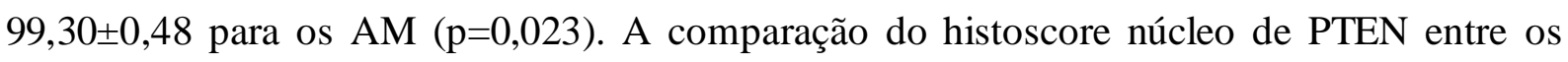
OKC $(4,90 \pm 1,36)$ e os $\operatorname{AM}(11,20 \pm 0,53)$ evidenciou significância estatística $(p=0,003)$, assim como na comparação do histoscore citoplasma de PTEN $(\mathrm{p}=0,011)$ e na correlação entre as porcentagens de imunomarcação citoplasmática de PI3K e PTEN nos OKC (p=0,019). Podese concluir que PI3K e PTEN estão presentes nos constituintes epiteliais dos OKC e AM. Sugere-se que a via PI3K/PTEN pode está ativa em OKC em virtude da correlação negativa de PI3K e PTEN ser encontrada nesse cisto odontogênico.

Palavras-chave: Ameloblastoma. Ceratocisto odontogênico. Imunohistoquímica. PI3K. PTEN. 


\begin{abstract}
Odontogenic cysts are relatively common lesions that cause bone destruction in the jaws. They are classified according to their origin in: developmental cysts, including odontogenic keratocyst (OKC), or in inflammatory cysts. Odontogenic tumors correspond to a complex group of lesions of different histopathological types and clinical behaviors, being classified according to their origin. Among tumors of odontogenic epithelial origin, ameloblastoma (AM) is often significant, tumor due to its slow growth and clinical feature of local invasiveness. The pathogenesis of odontogenic cysts and tumors is still little elucidated and studies aim to identify mechanisms and pathways involved in the formation and progression of these lesions. In this context, the PI3K / AKT / PTEN pathway has been analyzed in some odontogenic cysts and tumors in order to understand mechanisms involved in these lesions. Thus, the present study aimed to analyze and compare the immunohistochemical expression of PI3K and PTEN in odontogenic keratocysts and ameloblastomas. The sample consisted of $10 \mathrm{OKC}$ and $10 \mathrm{AM}$. Immunohistochemical screening was performed using the anti-PI3K (1:400) and anti-PTEN (1:400). Mean \pm SEM of the calculated cell counts and histories were expressed and analyzed by the Mann-Whitney test, followed by Dunn's post-test and correlated using Spearman's correlation. The categorical data were expressed as absolute frequency and compared using Fisher's Exact or Pearson's Chi-square test. Immunohistochemical analysis showed positive immunoblot in all cases of the sample. The total nuclear-stained cells for OKC PTEN were 39.21 \pm 12.38 immunopositive cells and AM were $93.60 \pm 2.45$ ( $\mathrm{p}<0.001)$. The cytoplasmic immunoexpression of PTEN to OKC was $87.35 \pm 5.72$ cells immunolabelled and $99.30 \pm 0.48$ for AM $(\mathrm{p}=0.023)$. The comparison between the histoscore nucleus of PTEN in the OKC $(4.90 \pm 1.36)$ and in the AM $(11.20 \pm$ 0.53) $(\mathrm{p}=0.003)$, also evidencing statistical significance in the comparison of histoscore cytoplasm $(\mathrm{p}=0.011)$. The correlation between the percentages of PI3K and PTEN immunoblotting in OKC showed a statistically significant relationship between the percentage of cytoplasmic immunoexpression $(\mathrm{p}=0.019)$. Considering the results obtained in this research, it can be concluded that PI3K and PTEN are present in the epithelial constituents of OKC and AM. It is suggested that the PI3K / PTEN pathway may be active in OKC because the negative correlation of PI3K and PTEN is found in this odontogenic cyst.
\end{abstract}

Key words: Ameloblastoma. Immunohistochemistry. Odontogenic keratocyst. PI3K. PTEN. 


\section{LISTA DE FIGURAS GERAL}

Figura 1 - Representação esquemática das isoformas de PI3K ........................................... 17

Figura 2 - Via PI3K/AKT/PTEN ................................................................................ 18

Figura 3 - Representação esquemática das isoformas de AKT/ PK ......................................... 19

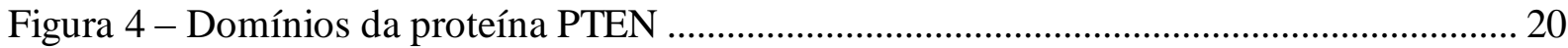




\section{LISTA DE FIGURAS DO ARTIGO}

Figura 1- A) Fotomicrografia exibindo imunoexpressão citoplasmática e membranar de PI3K no revestimento epitelial de OKC. B) Fotomicrografia exibindo imunoexpressão nuclear e citoplasmática de PTEN no revestimento epitelial de OKC. C) Fotomicrografia exibindo imunoexpressão citoplasmática e membranar de PI3K em AM unicístico. D) Fotomicrografia exibindo imunoexpressão nuclear e citoplasmática de PTEN em AM unicístico. E) Fotomicrografia exibindo imunoexpressão citoplasmática e membranar de PI3K em AM convencional. F) Fotomicrografia exibindo imunoexpressão nuclear e citoplasmática de PTEN em AM convencional (LSAB,400x) 


\section{LISTA DE TABELAS DO ARTIGO}

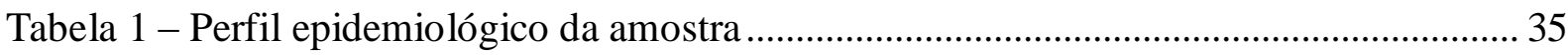

Tabela 2 - Porcentagens e histoscore de células imunomarcadas entre as variantes clínicas do

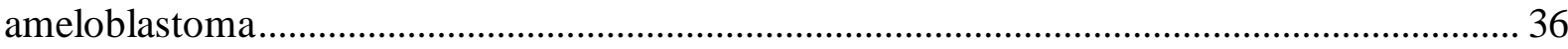

Tabela 3 - Porcentagens e histoscore de células imunomarcadas entre ceratocistos

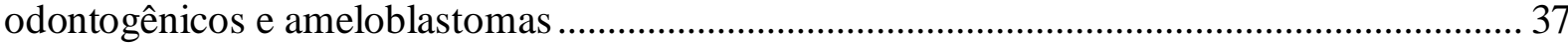

Tabela 4 - Correlação entre a imunoexpressão de PI3K e PTEN nos ceratocistos odontogênicos e ameloblastomas 


\section{LISTA DE ABREVIATURAS E SIGLAS}

AKT Do inglês Protein Kinase B

AM Ameloblastoma

BCL-2 Do inglês $B$-cell lymphoma 2

CEO Carcinoma Epidermoide Oral

CEP Comitê de Ética em Pesquisa

DAB 3.3' Diaminobenzidina

EGFR Do inglês Epidermal Growth Factor Receptor

FGFR Do inglês Fibroblast Growth Factor Receptor

HE Hematoxilina \& Eosina

HIF Fator Indutor de Hipóxia

LSAB Estreptoavidina-biotina

MMPs Metaloproteinases da matriz

MMP $1 \quad$ Metaloproteinases da matriz 1

MMP 2 Metaloproteinase da matriz 2

MMP 9 Metaloproteinases da matriz 9

mTOR Do inglês Mammalian Target of Rampamycin

mTORC1 Do inglês mTORC complex 1

mTORC2 Do inglês mTORC complex 2

OKC Do inglês Keratocystic Odontogenic

p-AKT AKT fosforilado

PCNA Do inglês Proliferating Cell Nuclear Antigen

PI3K Do inglês Phosphatidylinositol-3-Kinase

PIP2 Do inglês Phosphatidylinositol-4,4-bisphosphate

PIP3 Do inglês Phosphatidylinositol (3,4,5)-triphosphate

PTEN Do inglês Phosphatase and Tensin homolog

RTK Receptores Tirosina Quinase do inglês Receptor Tirosin Kynases

TGF- $\alpha \quad$ Fator de transformação de crescimento $\alpha$

TGF- $\beta 1 \quad$ Do inglês Transforming growth fator $-\beta 1$

TSG Genes Supressores Tumorais

UFC Universidade Federal do Ceará

VEGF Do inglês Vascular Endothelial Growth Factor 


\section{SUMÁRIO}

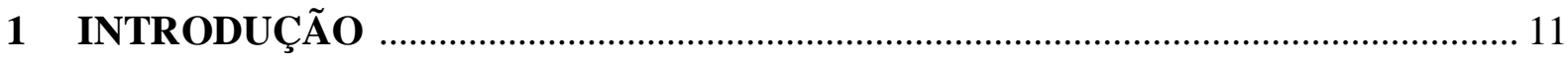

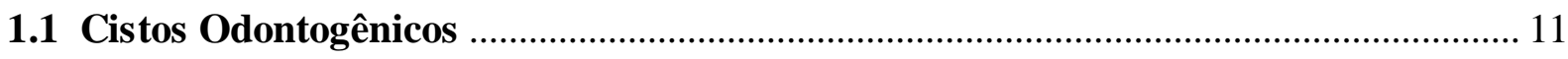

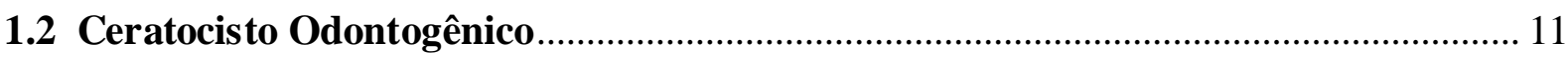

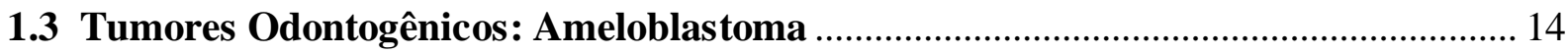

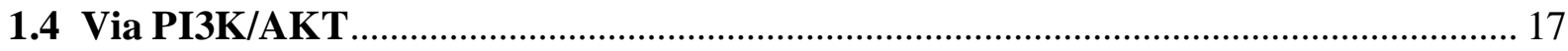

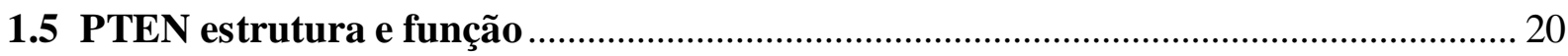

2 PROPOSIÇÃ

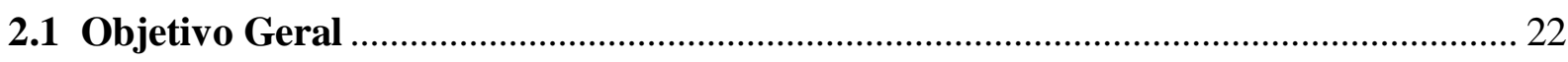

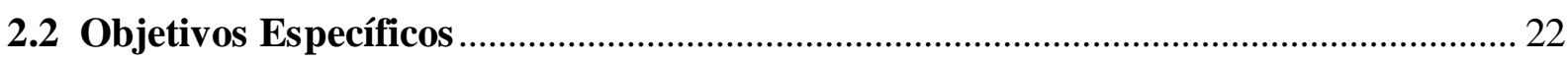

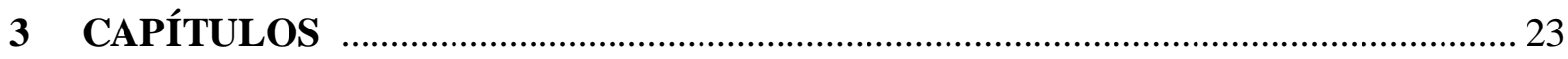

3.1 Avaliação da imunoexpressão de PI3K e PTEN em ceratocistos odontogênicos e

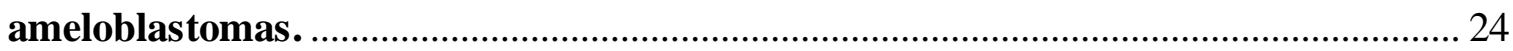

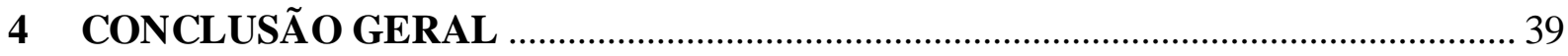

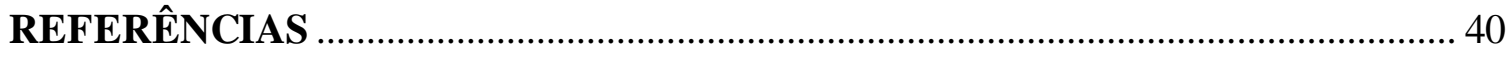

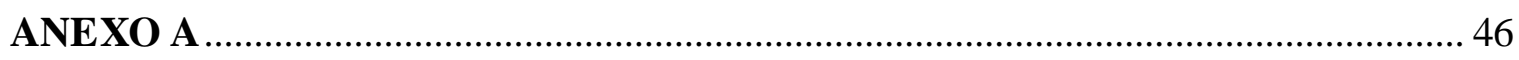

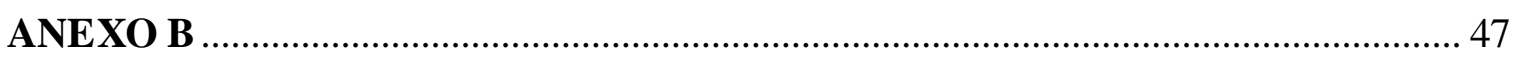

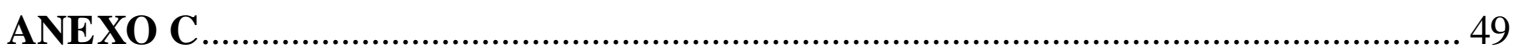




\section{INTRODUÇÃO}

\subsection{Cistos Odontogênicos}

Cistos são cavidades patológicas com conteúdo fluido ou semi-fluido em seu interior, sendo frequentemente revestidos por epitélio e suportados por tecido conjuntivo fibroso. Nos maxilares, os cistos podem ser classificados de acordo com a origem: em odontogênicos ou não odontogênicos (AVELAR et al., 2009; EL NAGGAR, et al. 2017; LO MUZIO et al., 2017).

Quando a formação cística dar-se a partir de inclusões epiteliais nas linhas de fusão dos processos embrionários, que dão origem ao processo maxilomandibular, os cistos são denominados não odontogênicos; por sua vez, quando resultam da proliferação de remanescentes epiteliais de estruturas relacionadas com a odontogênese, como a lâmina dentária, órgão do esmalte ou a bainha de Hertwig, são classificados como cistos odontogênicos (AVELAR et al., 2009; SOUZA et al., 2010).

A presença pura e simples de restos epiteliais seria insuficiente para explicar a formação de um cisto. É necessária a ação de um estímulo capaz de incitar e determinar a proliferação desses remanescentes. Destaca-se que é a partir da natureza destes estímulos, que ocorre a classificação dos cistos odontogênicos em cistos de desenvolvimento e inflamatórios (AVELAR et al., 2009; SHEAR et al., 2011).

São chamados de cistos odontogênicos inflamatórios, aqueles em que a inflamação age como desencadeador do desenvolvimento cístico. Faz parte deste grupo o cisto radicular, que corresponde ao cisto odontogênico mais comum nos maxilares (MOSQUEDA et al., 2002; AVELAR et al., 2009; SHEAR et al., 2011).

Algumas vezes, há conhecimento da ausência da participação de processos inflamatórios na patogênese de cistos odontogênicos, mas não se sabe ao certo qual estímulo deu início à formação da entidade cística. Nesses casos, são definidos como cistos de desenvolvimento, como o ceratocisto odontogênico (MOSQUEDA et ., 2002; AVELAR et al., 2009; EL NAGGAR, et al. 2017).

\subsection{Ceratocisto Odontogênico}

O Ceratocisto Odontogênico (OKC: odontogenic keratocyst) é um cisto odontogênico, intra-ósseo, com potencial para agressividade e comportamento infiltrativo (PEIXOTO et al., 2009). Na década de 50, Phillipsen descreveu essa lesão como ceratocisto odontogênico, que 
apresentava taxa de prevalência variando de $3 \%$ a $10 \%$ entre todos os cistos (PHILLIPSEN,1956).

A primeira tentativa de classificar as lesões císticas odontogênicas foi publicada em 1971 após um esforço conjunto, durante 5 anos, da Organização Mundial de Saúde (OMS). Com os avanços na técnica imunohistoquímica e biologia molecular durante a última década, uma segunda edição atualizada da OMS foi publicada em 1992. Em 2005, uma outra classificação foi proposta, em que o ceratocisto odontogênico foi incluído como tumor odontogênico benigno (BARNES et al., 2005). Já em 2017, na quarta edição da classificação da OMS, diversas mudanças foram propostas, uma das quais a reclassificação do ceratocisto odontogênico em cisto, uma vez que, embora apresente crescimento agressivo e recorrência após tratamento, alterações moleculares, como a mutação no gene PTCH, apresentam-se bem evidenciadas em $85 \%$ dos casos de ceratocistos odontogênicos associados à Síndrome Nevoide do Carcinoma Basocelular, e apenas 30\% dos ceratocistos não associados à síndrome apresentam a mutação do PTCH, o que não justificaria classificar essa lesão como uma neoplasia, uma vez que existem outras alterações moleculares (WRIGHT; VERED, 2017).

O conceito neoplásico dessa lesão era apoiado por estudos moleculares que demonstraram perda de heterozigosidade, mutações ou metilações de genes supressores tumorais, principalmente nos genes p16, p53, PTCH1, MCC, TSLC1, LTAS2 e FHIT (AGARAM et al., 2004; HENLEY et al., 2005; MALCIC et al., 2008). Contudo, algumas dessas alterações, como a perda da heterozigosidade, já foram evidenciados em outras lesões císticas (WRIGHT; VERED, 2017). Tais estudos também comprovaram o alto índice de imunoexpressão de marcadores de proliferação e anti-apoptóticos como PCNA, p53, p63 e BCL2 (DE PAULA et al., 2000; HAYASHITA et al., 2005; IORIO et al., 2005; LO MUZIO et al., 2017).

Quanto às características epidemiológicas, o OKC acomete pacientes que variam da infância ao adulto e idoso, sendo que $60 \%$ dos casos afetam a faixa etária de 10 a 40 anos (VAROLI et al., 2010). Güler (2012) relatou que o OKC pode ocorrer em ambos os sexos, com predileção para o sexo masculino e de idade entre 10 a 30 anos. Myong et al. (2001) realizou um trabalho com 256 casos, em que constataram a predileção de $58,6 \%$ pelo sexo masculino em pacientes da terceira década de vida. Antunes et al. (2007) em uma análise de 69 casos no período de 1992 a 2007, constatou com relação ao sexo que 56\% eram masculinos e 44\% femininos e a prevalência da idade era da segunda década à quarta década (CUNHA et al., 2016).

A incidência desta lesão na mandíbula é de 3 a 4 vezes maior que na maxila, com preferência pela região dos terceiros molares inferiores e ângulo da mandíbula, de onde se estende para o ramo ascendente (MALLMANN et al., 2012). Antunes et al. (2007), no seu 
estudo com 69 casos, observaram que $75 \%$ das lesões acometeram a mandíbula (52 casos) e 25\% a maxila (17 casos). Em estudo realizado com 43 lesões, 20 (46,5\%) estavam associados com terceiros molares impactados, 10 casos $(23,3 \%)$ presentes na maxila e 33 casos $(76,7 \%)$ na mandíbula (GÜLER et al., 2012).

Sinais e sintomas estão na maioria das vezes ausentes, sendo geralmente descobertos em exames radiográficos de rotina. Em casos de lesões mais extensas, pode ser observada tumefação, drenagem ou dor associada, aumento de volume de tecidos moles e tecido ósseo, parestesia e mobilidade de dentes envolvidos pela lesão (MALLMANN et al.,2012).

Radiograficamente, apresenta-se como uma área radiolúcida bem diferenciada, com cortical marginal bem definida. Lesões grandes particularmente na região posterior e ramo ascendente da mandíbula podem apresentar, em torno de 25 a $40 \%$ dos casos, associação com um dente incluso, além de deslocamentos dentários, reabsorção e extrusão de dentes envolvidos (ANTUNES et al., 2007; MALLMANN et al., 2012).

Acredita-se que o OKC é originado a partir de restos da lâmina dentária, tendo revestimento em epitélio escamoso estratificado, uma camada de 6 a 8 células de espessura e um revestimento paraceratinizado de aspecto corrugado, apresentando uma interface plana com a cápsula fibrosa. As células basais colunares apresentam polaridade nuclear invertida, uma importante característica, e cistos satélites em sua cápsula podem ser encontrados em alguns casos (SHEAR, et al., 2011; GÜLER et al., 2012; CUNHA et al. 2016, EL NAGGAR, et al., 2017).

Vários métodos de tratamento vêm sendo sugeridos no intuito de encontrar uma terapia que seja a mais conservadora possível e, ainda assim, garanta baixos índices de recidiva. Grandes ressecções do tecido ósseo envolvido pela lesão provocam mutilações e são altamente debilitantes além de acarretar complexos procedimentos de reconstrução e reabilitação, sem contar os agravos de ordem psicológica (OCAÑA et al., 2009). Os tratamentos para os OKC permanecem controversos, abrangem desde a marsupialização e enucleação, que podem ser combinadas com terapias adjuvantes como a crioterapia e a solução de Carnoy, à ressecção marginal ou radical (ZHAO et al., 2012).

Peixoto et al. (2009) relataram que existem discordâncias sobre o tratamento do OKC, variando de acordo com as características individuais de cada caso, dentre eles a idade do paciente e localização da lesão. A ressecção é um método de tratamento usado quando a proservação não pode ser realizada de forma adequada ou para tratar lesões de múltiplas recorrências. 
O índice de recorrência varia de aproximadamente $22 \%$ a $60 \%$, e pode ocorrer em até cinco anos após a remoção da lesão, embora existam casos de recorrências que ocorrem até 10 anos após a cirurgia de remoção. Isto explica a importância de um acompanhamento clínicoradiográfico prolongado do paciente após a remoção da lesão. Estudos relatam que a presença de cistos satélites e restos de epitélios odontogênicos têm sido atribuídos como causas para recorrência do $\mathrm{OKC}$, sendo determinante para o tratamento a observação aos parâmetros clínicos, radiográficos e histopatológicos (GÜLER et al., 2012; CUNHA et al., 2016).

\subsection{Tumores Odontogênicos: Ameloblastoma}

Os tumores odontogênicos constituem um grupo heterogêneo de lesões com características histopatológicas e manifestações clínicas diversas, estendendo desde proliferação hamartomatosa, tumores benignos não-agressivos, agressivos e tumores malignos. Em virtude da diversidade de lesões que podem originar-se dos tecidos odontogênicos, diversos esquemas de classificação foram publicados na tentativa de definir seus critérios diagnósticos (BUCHNER et al., 2006). Entretanto, a classificação mais amplamente aceita é a da OMS, a qual classifica os tumores odontogênicos em 3 grupos: tumores odontogênicos epiteliais, mistos e do ectomesênquima (EL NAGGAR et al., 2017).

Os tumores odontogênicos epiteliais são compostos por epitélio odontogênico sem a participação de ectomesênquima odontogênico. Diversos tumores distintivamente diferentes são incluídos nesse grupo, sendo o ameloblastoma a lesão que apresenta maior frequência clínica e comportamento agressivo (EL NAGGAR et al., 2017).

A categoria dos tumores odontogênicos mistos apresenta origem no epitélio odontogênico em proliferação no ectomesênquima, que lembra a papila dentária. Algumas dessas lesões mostram variados graus de efeitos indutores por parte do epitélio no mesênquima, levando à formação de variadas quantidades de esmalte e/ou dentina. Os odontomas são os tumores mais comumente encontrados, cerca de 67\% (COSTA et al., 2016; EL NAGGAR et al., 2017).

Os tumores odontogênicos do ectomesênquima são compostos principalmente por elementos do ectomesênquima. Apesar do epitélio odontogênico poder estar presente nessas lesões, ele não apresenta um papel essencial em sua patogênese. Em alguns casos, os achados histopatológicos isoladamente não são suficientes para distinguir entre as lesões neoplásicas e as anomalias de desenvolvimento e, portanto, as características clínicas e radiográficas são frequentemente de considerável auxílio na realização de tal distinção (EL NAGGAR et al., 2017). 
O ameloblastoma é o neoplasma benigno mais frequente derivado do epitélio odontogênico, caracterizando-se por ser localmente invasivo e possuir um comportamento agressivo. Desenvolve-se a partir dos remanescentes da lâmina dental e do órgão dentário (NAGI; SAHU; RAKESH, 2016; EL NAGGAR et al., 2017).

Os ameloblastomas representam cerca de $1 \%$ do total de tumores orais epiteliais odontogênicos e $11 \%$ de todos os tumores odontogênicos. Não apresentam predileção de gênero e registram um pico de incidência entre a $3^{a}$ e $5^{a}$ década de vida. A maioria dos ameloblastomas localiza-se na mandíbula (80\%), mais frequentemente na região posterior do corpo ou nos ramos ascendentes. Clinicamente, a queixa mais frequente é a presença de tumefação indolor, sendo muitas vezes diagnosticados em exames de rotina (COSTA et al., 2016).

Na quarta edição da OMS, 2017, o ameloblastoma sofreu modificações na terminologia e classificação com a introdução de perspectivas baseadas em atualizações sobre estudos genéticos atuais. A classificação foi simplificada para ameloblastoma, sem necessidade de diferenciação, ameloblastoma unicístico (AU) e tipos extra-ósseos/periféricos. A terminologia "sólido/multicístico" para o ameloblastoma convencional foi descartada, porque parece não existir significância biológica e poderia levar à confusão com o ameloblastoma unicístico. $\mathrm{O}$ ameloblastoma desmoplásico foi reclassificado como um subtipo histológico e não como uma entidade clinicopatológica, uma vez que, apesar de suas características clínicas e radiográficas serem padronizadas, ele se comporta como qualquer ameloblastoma convencional (WRIGHT; VERED, 2017).

O aspecto imaginológico é variável, podendo ser multilocular ou unilocular, embora a sua diferenciação apenas pelas características radiológicas algumas vezes não seja possível. O ameloblastoma convencional assume a forma de uma lesão radiolúcida multilocular, com aspecto de "bolhas de sabão", que pode apresentar septos espessos (LO MUZIO et al., 2017).

Diversos subtipos microscópicos de ameloblastoma convencional são reconhecidos, mas esses padrões microscópicos geralmente apresentam pouca relação com o comportamento do tumor. Os padrões folicular e plexiforme são os mais comuns. Padrões histopatológicos menos comuns incluem os tipos acantomatoso, de células granulares, desmoplásico e de células basais (EL NAGGAR, et al., 2017).

O padrão histopatológico folicular é o mais comum, evidenciando ilhas de epitélio que lembram o epitélio do órgão do esmalte em meio a um estroma maduro de tecido conjuntivo fibroso. Os ninhos epiteliais consistem em uma região central de células angulares arranjadas frouxamente, lembrando o retículo estrelado de um órgão do esmalte. Uma única camada de 
célu las colunares altas, semelhantes a ameloblastos, cerca essa região central. Os núcleos dessas célu las estão localizados no polo oposto à membrana basal (EL NAGGAR et al., 2017).

O tratamento do ameloblastoma varia de conservador a radical, com a ressecção da mandíbula dependendo do tamanho e localização da lesão. A taxa de recorrência após tratamento conservador varia de $36 \%$ a $93 \%$ nos tumores, sendo significativamente maior do que a taxa de recorrência para o tratamento radical, que varia de 8,3-21\% (SCHEPER et al., 2008).

O conhecimento do comportamento biológico do ameloblastoma é essencial para a seleção de uma abordagem terapêutica mais adequada e o estabelecimento de um prognóstico mais preciso. Tal fato vem despertando o interesse de pesquisadores em investigar, por meio de metodologias diferentes, os aspectos relacionados com a biologia molecular das populações de células tumorais em uma tentativa de elucidar pontos que ainda permanecem obscuros (MATOS et al., 2012).

Estudos imunohistoquímicos relataram a expressão de MMP-1, -2, -7, -9 e -26, além dos inibidores teciduais de metaloproteinase (TIMP)-1 e -2 em ameloblastomas (MATOS et al., 2012). Gadbail et al. (2011) verificaram uma maior positividade de Ki-67 e uma menor expressão de p53 em ameloblastomas do que em OKC.

No estudo de De Vicente et al.(2010), comparou-se o padrão de expressão de EGFR, ciclina D1, Ki-67, p-53 e antígeno carcinoembrionário (CEA) no revestimento epitelial de ceratocistos odontogênicos, cistos dentígenos, cistos radiculares e ameloblastomas. Neste estudo, foram evidenciadas diferenças estatisticamente significativas entre a expressão de ciclina D1 em ceratocistos odontogênicos, cistos radiculares e ameloblastomas. As células proliferativas foram significativamente mais prevalentes em ceratocistos odontogênicos com uma porcentagem média de núcleos marcados positivamente com Ki-67 de 40\%. Já nas outras lesões, a imunomarcação de Ki-67 foi de 17\% nos cistos dentígeros, 15,5\% nos cistos radiculares e 7,8 \% em ameloblastomas.

Vários estudos ressaltam que a patogênese dos ameloblastomas envolve diversos mecanismos, sendo investigada também a avaliação de padrões de expressão alterados de PI3K, PTEN, AKT, pS6K e marcadores ERK. Evidências científicas podem determinar modalidades de regulação positiva da via PI3K/AKT/mTOR em ameloblastomas, com foco nos fatores de crescimento, receptores tirosina-quinases, mutações RAS, ativação de PI3K ou amplificação de genes de AKT (SCHEPER et al., 2008). Nodit et al. (2004) evidenciaram por meio de análise molecular uma perda alélica de PTEN em $62 \%$ do total dos casos de tumores ameloblásticos.

Scheper et al. (2008) demonstraram que os ameloblastomas apresentam alterações na expressão proteica de moléculas de sinalização, as quais apresentam papel significativo no 
crescimento e sobrevivência de células neoplásicas, destacando que a análise imunohistoquímica de PTEN, AKT e pS6K pode ser uma importante ferramenta para o diagnóstico e para a determinação da agressividade dos ameloblastomas.

\subsection{Via PI3K/AKT}

A proteína PI3K pertence à família de lipídios-quinases presentes no meio intracelular (GIUDICE; SQUARIZE, 2014) e é dividida em 3 classes (Classe I, Classe II e Classe III) de acordo com seus achados estruturais, distribuição tecidual, mecanismos de ativação, função e substratos lipídicos específicos in vivo (GIUDICE; SQUARIZE, 2014).

A classe I PI3K é categorizada em IA e IB (Figura 1), sendo a classe IA PI3K a mais implicada no câncer. PI3K é constituído por um domínio catalítico p110 e um domínio regulador p85. Existem três isoformas de p110, nomeadamente p110 $\alpha$ (codificado por PIK3CA), p110 $\beta$ e

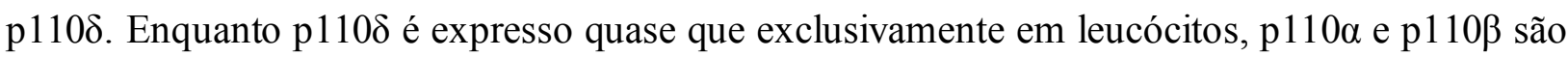
expressos de forma ubíqua em todos os tipos de células. Nos seres humanos, a subunidade reguladora PI3K 1 (PIK3R1), PIK3R2 e PIK3R3 codificam p85 $\alpha$ (ou sua variante de empalme p55 $\alpha$ ou p50 $\alpha$ ), p $85 \beta$, e p55 $\gamma$, respectivamente (MUKOHARA, 2015).

Figura 1 - Representação esquemática das isoformas de PI3K-IA.

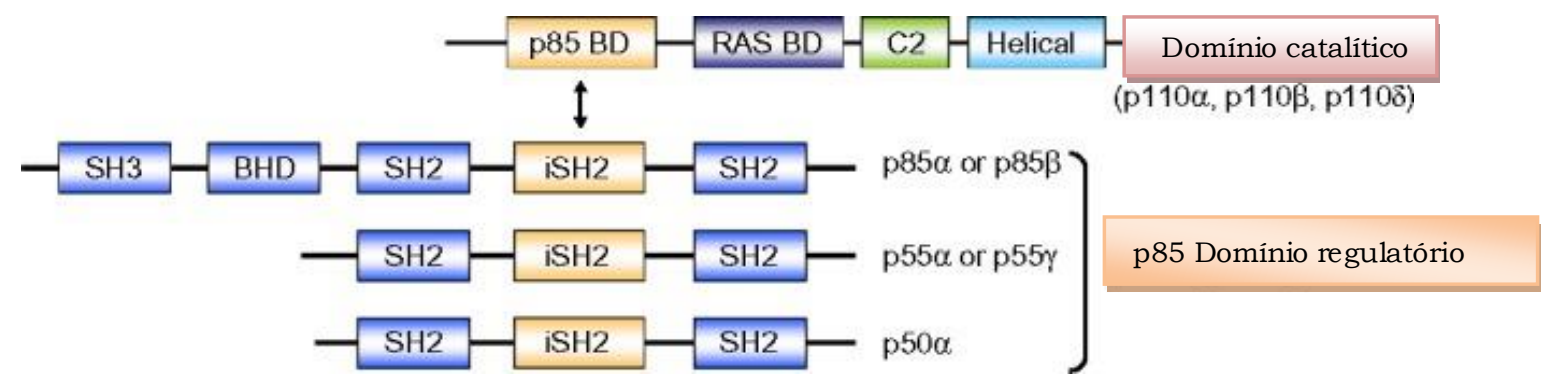

Fonte: Adaptado de Mukohara (2015).

A via PI3K tem início quando suas classes são ativadas. A classe IA torna-se ativa quando há a ligação de um ligante a um receptor, por exemplo RTK, EGFR, FGFR ou IGF-1R, localizado na membrana plasmática da célula (PORTA; PAGLINO; MOSCA, 2014). Uma vez ativados e presentes na membrana plasmática, os subprodutos da classe IA de PI3K irá fosforilar primariamente PIP2 (fosfatidioinositol-4,4-bifosfato), gerando o produto PIP3 (PORTA; PAGLINO; MOSCA, 2014). A via PI3K possui ainda diversas outras repercussões nas células 
através da ativação de AKT, a qual regula uma série de processos envolvidos na sobrevida da célu la e na progressão do ciclo celular (Figura 2) (PORTA; PAGLINO; MOSCA, 2014).

Ensaios imunohistoquímicos e western-blot têm sido utilizados para detectar essas proteínas, seu papel na via PI3K-AKT-mTOR e estabelecer possíveis estratégias terapêuticas específicas para o tratamento de vários tumores. A sinalização de PI3K/AKT/mTOR está relacionado a várias funções celulares, controle de síntese proteica, crescimento celular, apoptose, proliferação e angiogênese (MARTINS et al., 2016).

Pesquisas anteriores confirmam a expressão de receptores de fator de crescimento com atividade tirosina-quinase, incluindo o receptor do fator de crescimento epidérmico, receptores do fator de crescimento de fibroblasto e moléculas sinalizadoras da via Ras/MAPK em tumores odontogênicos, sugerindo que a sinalização do fator de crescimento contribui para a diferenciação de tecidos odontogênicos (KUMAMOTO; OOYA, 2007; SCHEPER et al., 2008). Isso sugere a importância de investigar vias de sinalização, como a PI3K/AKT nessas lesões.

Figura 2 - Via PI3K/PTEN

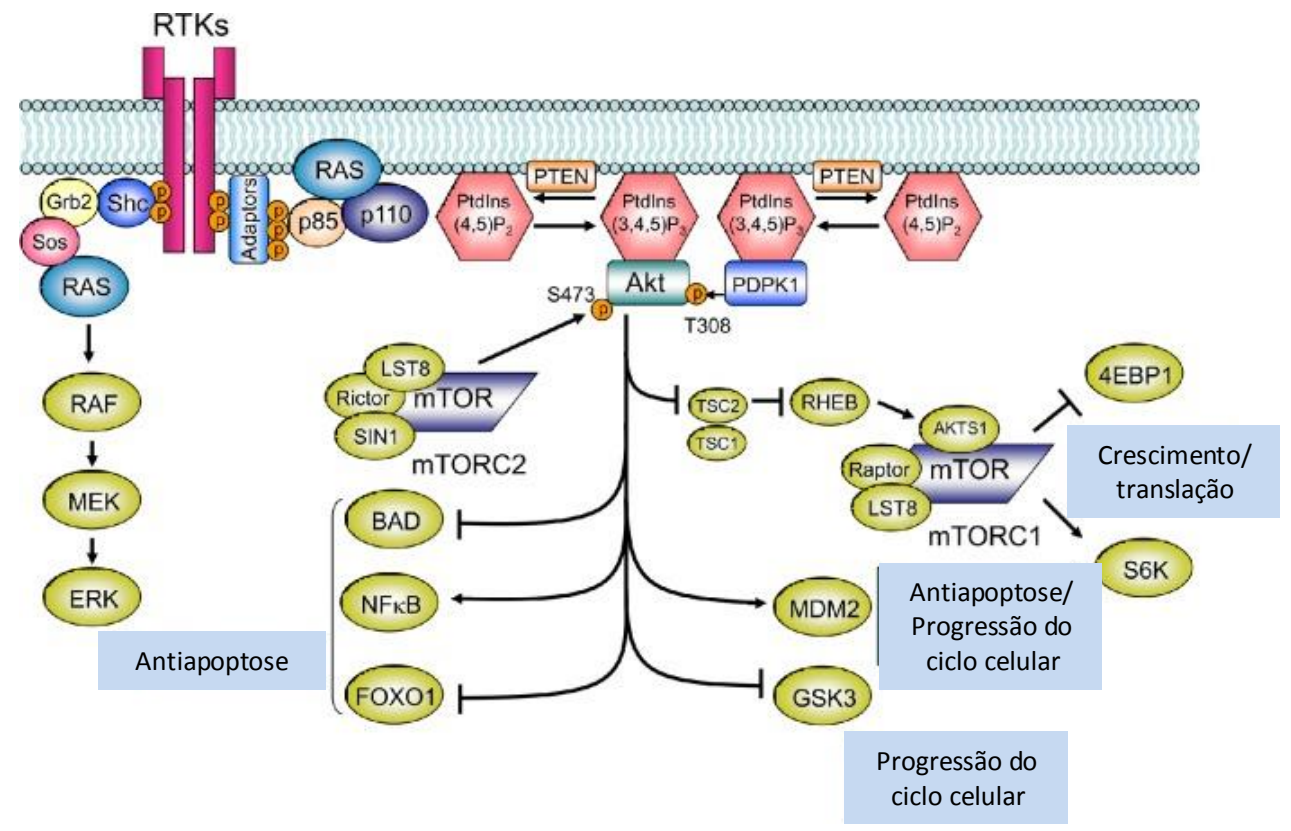

Fonte: Adaptado de Mukohara (2015).

Já a proteína AKT/PKB é uma serina/treonina quinase, pertencente à família de proteínas quinase que compartilham homologia estrutural dentro do seu domínio catalítico e possuem mecanismos semelhantes de ativação (SONG, OUYANG; BAO, 2005). Os genes AKT1, AKT2 e AKT3, conhecidos genericamente como AKT, codificam PKB (Proteína quinase B). As três isoformas de AKT, embora advindas de genes diferentes, compartilham mais de $80 \%$ de 
homologia em seus domínios ( $\mathrm{PH}$, catalítico e regulatório), havendo variações em alguns resíduos de aminoácidos e nas suas funções celulares (MADHUNAPANTULA; ROBERTSON, 2011) (Figura 3).

Figura 3 - Representação esquemática das isoformas de AKT/PKB e a variante PKB $\gamma 1$.

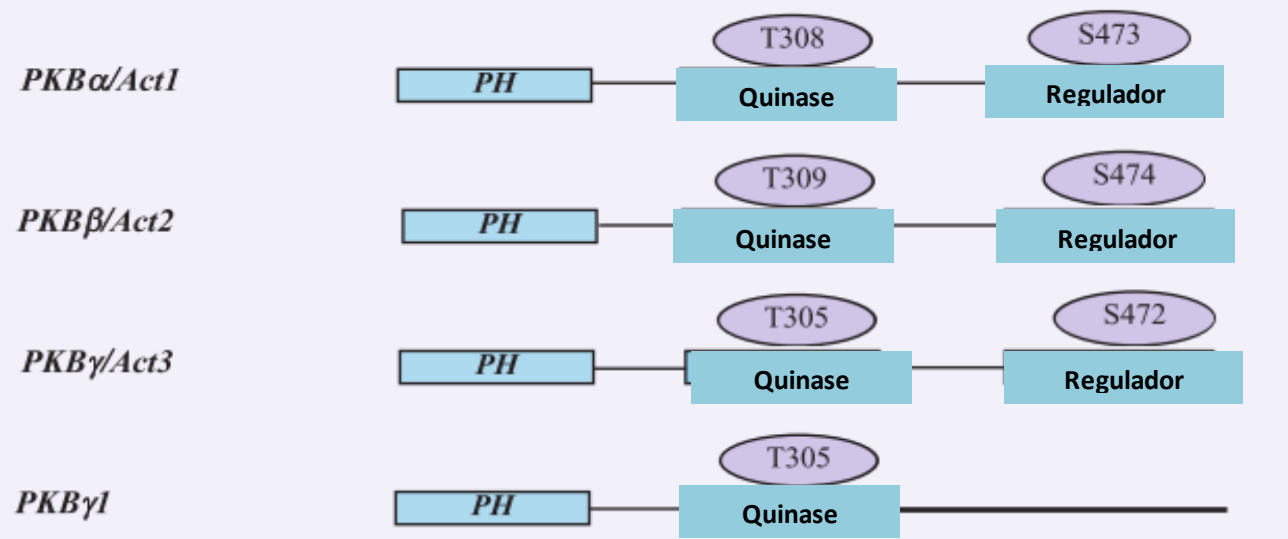

Fonte: Adaptado de Song, Ouyang e Bao (2005).

Quando receptores de fatores de crescimento são estimulados, a via PI3K é ativada, gerando a produção de PIP3 na membrana plasmática, o qual desencadeia a translocação de AKT do citoplasma para a membrana e se liga com o domínio PH de AKT (SONG, OUYANG; BAO, 2005). Estudos recentes mostram que PIP3 sozinho não é suficiente para proporcionar ligação segura de AKT à membrana plasmática, havendo a participação de um fosfolipídio membranar denominado PS (Fosfatidilserina) (HUANG et al., 2011). PS se liga ao domínio PH de AKT numa região diferente de ligação de PIP3 e promove uma mudança conformacional de AKT com exposição de T308 (Treonina 308) para a fosforilação por PDK1. Simultaneamente, o domínio RD também interage com PS, o que leva a uma outra abertura conformacional de AKT com exposição de S473 (serina 473) para sua fosforilação por mTOR (especificamente mTORC2). A proteína PDK2 (quinase 3'- fosfoinositide-dependente quinase 2) também pode fosforilar a porção S473 de AKT (MADHUNAPANTULA; ROBERTSON, 2011). Existe ainda uma ligação direta, porém mínima, de PIP3 com o domínio RD de AKT, que é suficiente para induzir uma abertura conformacional de RD e exposição de S473 (HUANG et al., 2011).

Fisiologicamente, $A K T$ controla diversas funções celulares, como crescimento, sobrevida, proliferação e metabolismo (GONZALEZ; MCGRAW, 2009) (Figura 1). Os membros da família de AKT (AKT1, AKT2 e AKT3) exercem estas funções a depender do tipo celular (GONZALEZ; MCGRAW, 2009; MADHUNAPANTULA; ROBERTSON, 2011), o que explica como AKT controla tantas funções de modo específico e direcionado a cada célula (GONZALEZ; MCGRAW, 2009). O papel e atuação de AKT demonstra a importância de se 
investigar proteínas relacionadas com sua ativação, como PI3K, em cistos e tumores odontogênicos.

\subsection{PTEN estrutura e função}

O PTEN, especificado por MMAC1 (Mutaded in Multiple Advanced Cancer 1) e TEP1 (Telomerase Protein Component 1) é uma proteína composta por 403 aminoácidos que contém um domínio fosfatase $\mathrm{N}$-terminal, um domínio C2 e uma região caudal C-terminal que contém múltiplos sítios de fosforilação (Figura 4). O PTEN também contém duas sequências PEST (degradação) e um domínio PDZ (liga proteínas regulatórias e de ligação à membrana) na região caudal e esses elementos são indispensáveis para a função de supressor tumoral. A função das sequências PEST é segmentar proteínas com meia vida intracelular curta para degradação proteica. A deleção dessas sequências no PTEN, no entanto, leva à diminuição da expressão da proteína, talvez pelo enovelamento das proteínas comprometidas (SIMPSON; PARSONS, 2001).

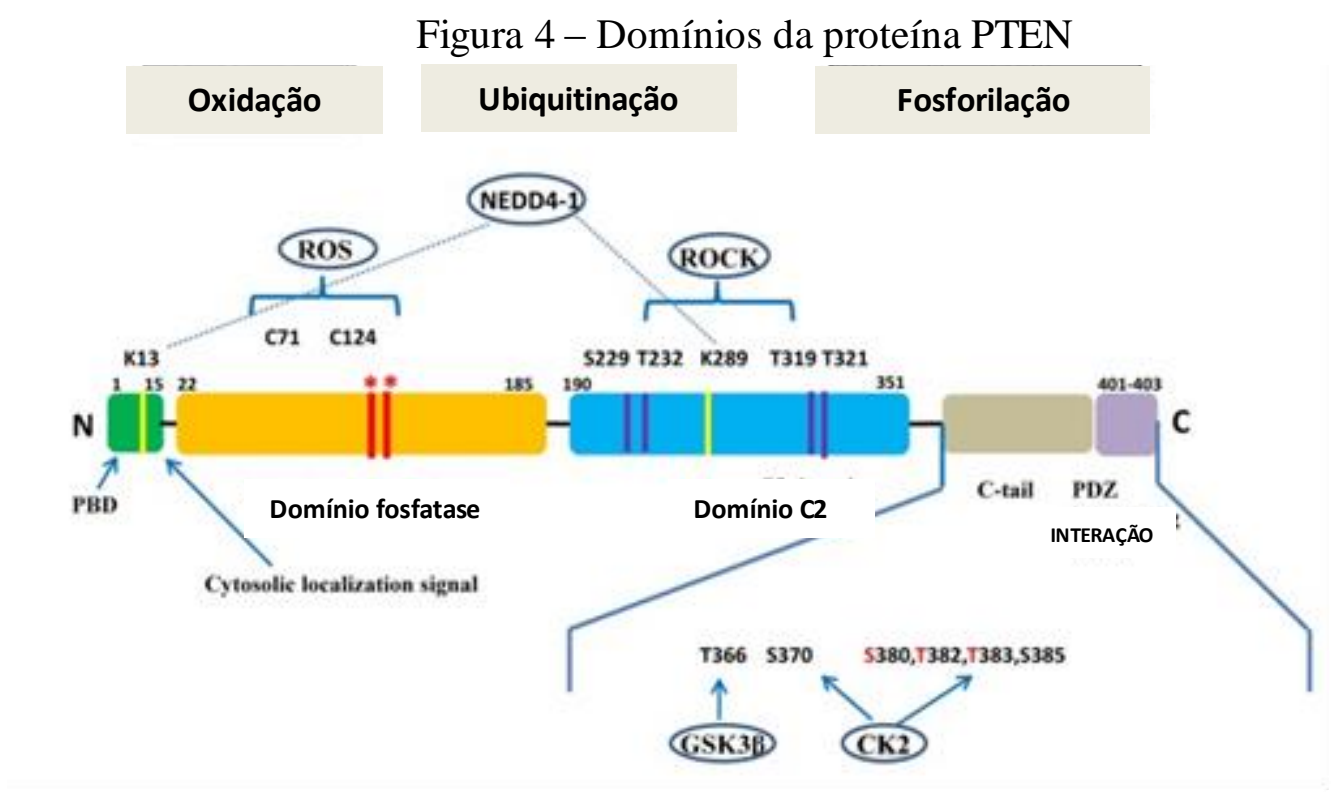

Fonte: Wang, Huang e Young (2011).

O domínio fosfatase tem características que se assemelham às fosfatases de especificidade dual, que são capazes de desfosforilar tanto os resíduos serina e treonina, quanto os de tirosina. Apesar de possuir especificidade dual, seu principal substrato in vivo é o PIP3, um produto direto da atividade PI3K (ANGADI; KRISHNAPILLAI, 2012). A ativação de $P I 3 K$ por sinalizações dependentes dos fatores de crescimento leva à síntese de PIP3, que é desfosforilado por PTEN a PIP2. A presença do PTEN, portanto, mantém os níveis de PIP3 baixos, enquanto 
que sua ausência promove o aumento da concentração de PIP3 e da sinalização PI3K/AKT (Figura 4) (GIUDICE; SQUARIZE, 2014).

Quando o PTEN é deletado, mutado ou ainda inativado, há a desregulação de $A K T$ através de efetores $P I 3 K$. Essa sobreregulação finalmente inibe a apoptose, levando à continuada sobrevivência e proliferação celular, contribuindo para a tumorigênese e predispondo para o desenvolvimento do câncer. A rede de sinalização PI3K-PTEN é crucial para uma adequada regulação da sobrevivência celular (DAHIA, 2000; YAMADA; ARAKI, 2001; ALYASIRI et al., 2012; ANGADI; KRISHNAPILLAI, 2012).

Mutações somáticas e supressão ou silenciamento epigenético que levam a perda de PTEN têm sido relatadas em uma variedade de lesões potencialmente malignas e cânceres humanos, incluindo câncer de próstata, mama, do endométrio, tireoide, melanoma, leucemia, linfoma e carcinoma epidermoide oral (CEO) (ALYASIRI et al., 2012; ANGADI; KRISHNAPILLAI, 2012; SNIETURA et al., 2012). Em muitas neoplasias, a supressão do PTEN coopera com outras alternâncias genéticas, contribuindo com a tumorigênese e podendo determinar um comportamento clínico mais agressivo do tumor (SNIETURA et al., 2012).

Nos cistos e tumores odontogênicos, o papel de PTEN ainda é pouco elucidado, sendo necessária uma melhor investigação da participação dessa proteína na patogênese dessas lesões. Kumamoto e Ooya (2007) demonstraram uma imunoreatividade para PTEN em células neoplásicas de ameloblastomas e tumor ameloblástico maligno, sugerindo que esta molécula suprime a via de sinalização de AKT nestes tumores epiteliais odontogênicos. Além disso, a expressão do nível de PTEN nos ameloblastomas foi significativamente menor que nos germes dentários. 


\section{PROPOSIÇÃO}

A presente pesquisa teve como objetivos:

\subsection{Objetivo Geral}

Analisar a presença das proteínas PI3K e PTEN em ceratocistos odontogênicos e ameloblastomas.

\subsection{Objetivos Específicos}

- Avaliar a expressão imunohistoquímica da proteína PI3K em ceratocistos odontogênicos e ameloblastomas;

- Avaliar a expressão imunohistoquímica da proteína PTEN em ceratocistos odontogênicos e ameloblastomas;

- Estabelecer uma correlação comparativa entre a imunoexpressão de PI3K e PTEN em ceratocistos odontogênicos e ameloblastomas;

- Identificar a frequência das características clínicas coletadas, tais como sexo, idade e sítio de localização, correlacionando-as entre si. 


\section{CAPÍtulos}

Esta dissertação está baseada no Artigo 46 do Regimento Interno do Programa de Pós-Graduação em Odontologia da Universidade Federal do Ceará (Anexo A), que regulamenta o formato alternativo para dissertações de mestrado e teses de doutorado e permite a inserção de artigos científicos de autoria ou coautoria do candidato. Por se tratar de pesquisa envolvendo seres humanos, o presente trabalho foi submetido ao Comitê de Ética em Pesquisa da Universidade Federal do Ceará/PROPESQ, com o parecer № 2.108.274, sendo aprovado em 08/06/17, sob o CAAE: 62974716.2.0000.5054 (Anexo B).

Diante disso, tal dissertação de mestrado é composta por um capítulo que contém um artigo científico, que será submetido à publicação no periódico Oral Surgery, Oral Medicine, Oral Pathology and Oral Radiology, ISSN: 2212-4403, (Anexo C), conforme descrito abaixo:

\section{AVALIAÇÃO DA IMUNOEXPRESSÃO DE PI3K E PTEN EM CERATOCISTOS ODONTOGÊNICOS E AMELOBLASTOMAS.}

\section{Autores:}

\section{Sthefane Gomes Feitosa}

Grau acadêmico: Estudante de Mestrado em Odontologia, Bacharel em Odontologia.

Afiliação institucional: Departamento de Clínica Odontológica, Setor de Diagnóstico Oral, Universidade Federal do Ceará, Fortaleza, Brasil.

\section{Karuza Maria Alves Pereira}

Grau acadêmico: Pós Doutora em Odontologia, Doutora em Patologia Oral, Mestre em Patologia Oral, Bacharel em Odontologia. Posição: Professora Adjunta IV da Universidade Federal do Ceará. Afiliação institucional: Departamento de Morfologia, Faculdade de Medicina, Universidade Federal do Ceará, Fortaleza, Brasil.

Autor de Correspondência: Karuza Maria Alves Pereira Endereço: Rua Delmiro de Farias, S/N, Rodolfo Teófilo - Fortaleza, Ceará, Brasil, CEP: 60430-350. Telefone: 55-85-3366 8471. E-mail: karuzaalves@yahoo.com.br 


\subsection{Capítulo 1: Avaliação da imunoexpressão de PI3K e PTEN em ceratocistos odontogênicos e ameloblastomas.}

\section{RESUMO}

Objetivo. Analisar a imunoexpressão de PI3K e PTEN em ceratocistos odontogênicos (OKC) e ameloblastomas (AM).

Desenho do Estudo. A amostra foi constituída por $10 \mathrm{OKC}$ e 10 AM. A verificação imunohistoquímica foi realizada utilizando anti-PI3K (Abcam®,1:400) e anti-PTEN (Abcam®, 1:400), analisando 05 campos de cada caso (400x). Foram expressas as médias \pm EPM das contagens das células imunopositivas e dos histoscores calculados pelo produto entre a intensidade e a porcentagem de células imunopositivas, sendo analisados pelo teste de MannWhitney, seguido do pós-teste de Dunn e correlacionados usando a correlação de Spearman. Os dados categóricos foram expressos em frequência absoluta e comparados pelo teste Exato de Fisher ou Qui-quadrado de Pearson $(\mathrm{p}<0,05)$.

Resultados. A análise imunohistoquímica evidenciou imunomarcação positiva em todos os casos da amostra. O total de células com marcação nuclear para PTEN de OKC foram

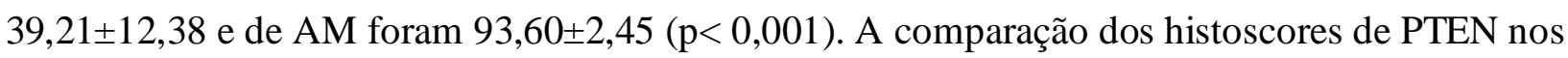
núcleos evidenciou maiores valores nos $\mathrm{AM}$ do que nos $\mathrm{OKC}(\mathrm{p}=0,003)$, assim como no histoscore citoplasma $(\mathrm{p}=0,011)$. Ademais, observou-se uma correlação negativa $(r=-0,721)$ na imunoexpressão citoplasmática de PTEN e PI3K nos OKC ( $\mathrm{p}=0,019)$.

Conclusões. Pode-se concluir que PI3K e PTEN estão presentes nos constituintes epiteliais dos OKC e AM, havendo uma maior imunoexpressão nuclear e citoplasmática de PTEN nos AM do que nos OKC. Além disso, a correlação entre PI3K/PTEN no citoplasma dos OKC pode sugerir uma possível participação da via PI3K/PTEN nessas lesões. No entanto, novos estudos são necessários para melhor elucidar o papel destas moléculas nos cistos e tumores odontogênicos.

Palavras-chave: Ameloblastoma. Ceratocisto odontogênico. Imunohistoquímica. PI3K. PTEN. 


\section{INTRODUÇÃO}

Os cistos odontogênicos são as lesões ósseo-destrutivas mais comuns nos maxilares. São cavidades patológicas revestidas por epitélio, originando-se de tecido epitelial odontogênico ou de seus remanescentes que respondem a determinados estímulos como citocinas e fatores de crescimento, contudo a patogênese exata de muitas destas lesões permanece incerta. Podem ser classificados de acordo com a origem em: cistos de desenvolvimento ou inflamatórios. Dentre os cistos de desenvolvimento, o Ceratocisto Odontogênico (OKC), reclassificado como cisto pela Organização Mundial de Saúde (OMS) em 2017, apresenta abordagem diferenciada devido às suas características histopatológicas e comportamento biológico distinto, apresentando, em alguns casos, caráter de agressividade e recidiva. ${ }^{1,2}$

Nesse contexto, outro grupo complexo são os tumores odontogênicos, os quais surgem dos tecidos de origem odontogênica e são classificados de acordo com a Organização Mundial de Saúde (OMS) em 3 grupos. O Ameloblastoma (AM), tumor de origem epitelial, é a lesão que apresenta maior representatividade clínica em virtude do seu crescimento invasivo e da sua frequência. Muitos estudos buscam investigar mecanismos que possam estar envolvidos na patogênese e progressão dos ameloblastomas, sendo atualmente uma das vias de sinalização a PI3K/AKT/PTEN, crucial em muitos aspectos de sobrevida e crescimento celular.

A via PI3K/AKT/PTEN é uma via complexamente interligada que pode ser considerada como única, interagindo também com muitas outras vias de sinalização ${ }^{3}$. A via provoca uma cascata de sinalização intracelular que começa com a ativação da molécula PI3K (Fosfatidioinositol-3 quinase) que, através de seu subproduto PIP3 (Fosfatidioinositol $(3,4,5)$ trifosfato), ativa AKT (Proteína quinase B). ${ }^{4}$ PTEN (Fosfatase e tensina homóloga) é um controlador negativo da via PI3K/AKT. ${ }^{5}$

A ativação da via de sinalização PI3K tem sido alvo de estudos recentemente em tumores odontogênicos, principalmente em tumores mais agressivos como o ameloblastoma. ${ }^{6}$ Entretanto, não existem estudos que avaliem a expressão imunoistoquímica de PI3K e PTEN em ceratocistos odontogênicos e ameloblastomas. Assim, diante da importância de estudar a participação destas proteínas no metabolismo dessas lesões, a fim de buscar mecanismos que melhor elucidem a patogênese e o crescimento, o propósito deste estudo é avaliar a imunoexpressão de PI3K e PTEN nessas lesões. 


\section{MATERIAL E MÉTODO}

Esta pesquisa obteve o parecer favorável do Comitê de Ética em Pesquisa do Departamento de Medicina Clínica da Universidade Federal do Ceará, sob o número do parecer 2.108.274. O presente trabalho é um estudo analítico, retrospectivo, observacional, transversal e uma avaliação imunohistoquímica de ceratocistos odontogênicos e ameloblastomas. A população do estudo foi constituída de casos dessas lesões de pacientes atendidos no Ambulatório de Estomatologia da Universidade Federal do Ceará, no período de Janeiro de 2011 a Setembro de 2017. Foram incluídos na amostra casos nos quais os blocos parafinados apresentavam material biológico suficiente para análise imunohistoquímica. Foram excluídos da amostra os casos de OKC e AM que, após análise histopatológica, demonstraram presença de inflamação. Diante desses critérios, a amostra foi constituída por 10 casos de OKCs e 10 AM conforme estudo de Chaisuparat et al., ${ }^{7}$ utilizado para o cálculo amostral, sendo adotado um poder de $90 \%$ e uma confiança de $95 \%$.

\section{ESTUDO IMUNOHISTOQUÍMICO}

Para realização do estudo imunohistoquímico, os espécimes foram seccionados com $3 \mu \mathrm{m}$ de espessura, montados em lâminas de vidro silanizadas e submetidos à técnica imunohistoquímica da estreptoavidina-biotina (Labeled Strept Avidin Biotin - LSAB). Essa técnica consistiu, resumidamente em: as secções passaram por dois banhos em xilol, durante cinco minutos cada; em seguida, foram imersas em três passagens de etanol decrescente, sendo posteriormente lavadas em água corrente; e, em seguida, passagem em água destilada. A recuperação antigênica foi realizada em câmara úmida pressurizada, onde as secções foram submetidas a temperaturas de até $125-126^{\circ} \mathrm{C}$, por 30 minutos em solução de recuperação antigênica citrato $\mathrm{pH}$ 6,0. Após retornar à temperatura ambiente, as secções foram imersas em solução de P.B.S/Tween, seguido pelo bloqueio com peróxido de hidrogênio a 3\%, durante 30 minutos. Os espécimes foram incubados com os anticorpos anti-PI3K (Clone ab86714, Abcam ${ }^{\circledR}$ ) e anti-PTEN (Clone ab 31392, Abcam ${ }^{\circledR}$ ), overnight, utilizando a diluição de 1:400 para os dois anticorpos, as lâminas foram submetidas ao anticorpo secundário LSAB Kit (DAKO®, Carpinteria, CA, USA), por 15 minutos à temperatura ambiente; em seguida, foi realizada a revelação em solução cromógena preparada com diaminobenzidina (diaminobenzidine 3.3'- DAB) durante 5 minutos. Os espécimes foram novamente lavados em água corrente e água destilada; a contracoloração foi realizada com hematoxilina e, depois, foram desidratadas em álcool e diafanizadas em xilol; para finalizar, realizou-se a montagem com lamínulas com resina Permount ${ }^{\circledR}$. Como controle positivo, utilizou-se amostra de 
adenocarcinoma de mama para PTEN e tecidomuscular para PI3K. Foi realizado o controle negativo, excluindo-se a aplicação do anticorpo primário. O parâmetro de positividade da marcação imunohistoquímica do antígeno, em todos os espécimes incluídos na amostra, consistiu nas células que exibiram coloração acastanhada nas regiões de citoplasma e/ou núcleo, considerando a intensidade da imunomarcação citoplasmática em intensa ou leve. Foram selecionados, aleatoriamente, cinco campos no aumento de 400x, visualizados através do microscópio óptico Leica ${ }^{\circledR}$ DM2000 e fotografados pela câmera Leica ${ }^{\circledR}$ DFC295 3.0 megapixels em máxima resolução. A análise quantitativa da imunoexpressão de PI3K e PTEN foi realizada por meio da contagem do número, em valores absolutos, tanto das células imunomarcadas quanto das células totais nos cinco campos com aumento de 400x, por um observador, em momentos distintos, através do programa Image $\mathbf{J}^{\circledR}$ (Image and Processing Analysis in Java Rasband, W.S., Image J, National Institutes of Health, Bethesda, Maryland, USA). Adicionalmente, as células imunopositivas foram avaliadas quanto à localização da imunomarcação celular para PI3K (membranar ou citoplasmática) e PTEN (nuclear ou citoplasmática), sendo realizada a contagem nos $\mathrm{OKC}$ das células epiteliais e nos AM das células colunares com polarização invertida do epitélio. A avaliação da intensidade da imunoexpressão foi feita por meio da análise do campo fotografado no aumento de 400x, também com o auxílio do programa Image $\mathbf{J}^{\circledR}$. A partir desta análise, a intensidade da imunoexpressão foi classificada em: sem expressão, leve (intensidade menor que o controle positivo) e intensa (intensidade maior ou igual ao do controle positivo). O histoscore $(\mathrm{H})$ foi calculado por uma avaliação semiquantitativa, considerando o produto contrapartida entre intensidade da imunomarcação e a porcentagem de células positivas. O nível de expressão de cada componente foi categorizado como baixo ou alto de acordo com o valor médio do escore de $\mathrm{H}$.

\section{ANÁLISE ESTATÍSTICA}

Os dados foram analisados no software Statistical Packcage for the Social Sciences (SPSS) versão 20,0 para Windows ${ }^{\circledR}$. Foram expressas as médias \pm EPM das contagens das células e dos histoscores calculados, os quais foram analisados pelo teste de Mann-Whitney, seguido do pós-teste de Dunn e correlacionados usando a correlação de Spearman. Os dados categóricos foram expressos em forma de frequência absoluta e comparados por meio do teste Exato de Fisher ou Qui-quadrado de Pearson. Para todos os testes, a significância estatística foi considerada em $\mathrm{p}<0,05$. 


\section{RESULTADOS}

Este estudo foi constituído por uma amostra de 20 casos, sendo 10 OKC e 10 AM. De acordo com as características clínicas dos dados coletados nos casos de OKC houve prevalência do sexo feminino, perfazendo $70 \%$ dos casos. Quanto à faixa etária, $80 \%$ dessas lesões acometeram indivíduos até a $2^{\mathrm{a}}$ década de vida. A mandíbula foi a localização anatômica mais acometida, totalizando $90 \%$ da amostra de $\mathrm{OKC}$, com predileção pela região posterior (60\%). No grupo de AM, houve discreta diferença entre os sexos, com percentual de $60 \%$ para o sexo feminino. A faixa etária acometida foi ampla, evidenciando uma prevalência de $80 \%$ acima da $2^{\text {a }}$ década de vida. A mandíbula foi a localização mais frequentemente observada, perfazendo um total de $90 \%$ dos casos, sendo a região posterior mais acometida, representando $70 \%$ dos casos de AM estudados (Tabela 1).

Quanto ao perfil de imunoexpressão, foi observada imunomarcação positiva em todos os casos estudados, tanto de $\mathrm{OKC}$ quanto $\mathrm{AM}$. Em relação à comparação entre o grupo total de $\mathrm{AM}$ e os OKC, observou-se que a porcentagem de células com marcação nuclear positiva para PTEN nos casos de AM $(93,60 \pm 2,45)$ foi maior do que nos casos de OKC $(39,21 \pm 12,38)$, com diferença significativa entre os grupos estudados $(\mathrm{p}<0,001)$ (Tabela 2). Entretanto, a imunoexpressão de PI3K foi semelhante no grupos, sem significância estatística.

Quando analisada a porcentagem de imunoexpressão citoplasmática de PTEN, os resultados observados também evidenciaram maior percentual de células imunopositivas para o grupo de AM $(99,30 \pm 0,48)$ (Figura 1D e 1F) em relação ao de OKC $(87,35 \pm 5,72)$ (Figura 1B), expressando diferença estatística entre as lesões $(\mathrm{p}=0,023)$ (Tabela 2).

A comparação entre o histoscore nuclear de PTEN entre os OKC $(4,90 \pm 1,36)$ e os casos de AM $(11,20 \pm 0,53)$ apresentou significância estatística $(\mathrm{p}=0,003)$, sendo evidenciada também significância estatística na comparação do histoscore citoplasmático $(\mathrm{p}=0,011)$ entre os OKC $(7,30 \pm 1,08)$ e os ameloblastomas $(11,20 \pm 0,53)$ (Tabela 2).

Quanto à análise da imunoexpressão da proteína PI3K, em relação à comparação entre o grupo total de AM e o grupo de OKC para a análise de células com imunomarcação membranar positiva para PI3K, foi evidenciado nos casos de OKC (Figura 1 A) porcentagem de 88,88 $\pm 4,91$ células imunopositivas e nos AM (Figura 1C e 1E) 86,67士4,07, sem diferença significativa estatisticamente $(\mathrm{p}=0,280)$ (Tabela 2). Quando comparada a porcentagem de imunoexpressão citoplasmática de PI3K, os resultados observados para o grupo de OKC foram de 99,72 $\pm 0,05$ células imunomarcadas e de 99,39 $\pm 0,20$ células para o grupo de $\mathrm{AM}$, valores que não expressaram diferença estatística entre os grupos $(\mathrm{p}=0,315)$ (Tabela 2$)$. 
O histoscore membranar de PI3K para OKC $(7,10 \pm 0,85)$ e para os casos $\mathrm{AM}(5,60 \pm 0,70)$ quando comparados não tiveram significância estatística $(\mathrm{p}=0,247)$, assim como o histoscore citoplasmático de PI3K ( $\mathrm{p}=0,353)$ entre os $\operatorname{OKC}(7,20 \pm 0,80)$ e os $\mathrm{AM}(6,00 \pm 0,67)$ (Tabela 2).

O grupo de AM foi estratificado em dois grupos de acordo com suas variantes clínicas, em convencional e unicístico. Na comparação da imunoexpressão de PI3K e de PTEN entre os grupos de ameloblastomas convencionais e unicísticos, evidenciou-se marcação positiva em todos os casos da amostra, mas sem significância estatística nas porcentagens de imunomarcações e nos histoscores (Tabela 3).

Além disso, a correlação entre as porcentagens de imunomarcações de PI3K e PTEN nos grupos de $\mathrm{OKC}$ e $\mathrm{AM}$ evidenciou uma correlação negativa $(\mathrm{r}=-0,721)$ e estatisticamente significante entre a porcentagem de imunoexpressão citoplasmática de PI3K e PTEN nos OKC $(\mathrm{p}=0,019)($ Tabela 4).

\section{DISCUSSÃO}

O ceratocisto odontogênico é um cisto odontogênico de desenvolvimento com características histopatológicas específicas, alta taxa de recorrência e comportamento clínico agressivo, podendo acometer diferentes faixas etárias e com predileção pela região posterior da mandíbula. ${ }^{2}$

No presente estudo, o perfil epidemiológico do grupo de OKC encontrado demonstrou diferença entre os sexos acometidos por esta lesão, sendo o sexo feminino o mais acometido (70\%), em conformidade com o estudo de Hormozi et al. ${ }^{8}$ No entanto, outros autores relataram predileção pelo sexo masculino. ${ }^{8,9}$ Em relação à faixa etária, indivíduos com idade entre a $1^{\mathrm{a}} \mathrm{e}$ a $2^{\text {a }}$ década de vida foram os mais acometidos nesta pesquisa (80\%). A região posterior da mandíbula foi o sítio mais frequentemente encontrado neste estudo, resultado semelhante às pesquisas realizadas anteriormente, ${ }^{11,7,12}$ provavelmente por estar associado ao grande número de terceiros molares impactados nessa localização anatômica.

Em relação aos tumores odontogênicos, o ameloblastoma representa um tumor benigno de origem do epitélio odontogênico, com características de agressividade e alta recidiva. O perfil epidemiológico do grupo de ameloblastomas demonstrou diferença entre os sexos acometidos por esta lesão, sendo o sexo feminino o mais acometido (60\%), como no estudo de Hertog et al. ${ }^{13}$ No entanto, o estudo de Milman et al. ${ }^{14}$ demonstrou predileção pelo sexo masculino. Em relação à faixa etária, indivíduos com idade acima de 20 anos foram mais acometidos nesta pesquisa (80\%), em conformidade com os estudos de Milman et al., ${ }^{14}$ Hertog et al. ${ }^{13}$ e El Naggar et al. ${ }^{2}$ A 
região posterior da mandíbula (70\%) foi o sítio mais frequentemente encontrado neste estudo, resultado semelhante a pesquisas realizadas anteriormente (Tabela I). ${ }^{13,15}$

Os OKC investigados neste estudo apresentaram comportamentos clínicos e perfis de imunomarcações distintos, no entanto todos os casos analisados apresentaram imunomarcação citoplasmática e/ou membranar positiva para a proteína PI3K e imunomarcação nuclear e/ou citoplasmática para PTEN. Hu et al. ${ }^{16}$ estudaram sobre a patogênese do OKC e evidenciaram que a via PI3K/AKT pode estar envolvida em mecanismos de crescimento celular, proliferação e apoptose nessas lesões.

No presente estudo, embora os níveis de imunorreatividade para PI3K e PTEN nos ameloblastomas convencionais e unicísticos sejam evidenciados em todos os casos e com uma expressão predominantemente intensa, não foi evidenciado significância estatística entre as porcentagens de imunomarcação e o histoscore no grupo dos AM. Esse evento pode sugerir que independente do comportamento clínico do AM, seja convencional ou unicístico, essas proteínas estão presentes no tumor, contribuindo para o aspecto de crescimento expansivo característico dessas lesões. A patogênese do AM parece se correlacionar com outros mecanismos celulares e com outras proteínas, os quais podem contribuir para o dado encontrado nesse estudo.

Kumamoto e Ooya $^{17}$ evidenciaram uma imunoexpressão de PI3K e PTEN predominantemente em células do epitélio odontogênico próximo à membrana, assim como na presente pesquisa (Figura 1). Além disso, mostraram que os níveis de imunorreatividade para PI3K foram ligeiramente maiores nos ameloblastomas do que nos germes dentários. Já a imunomarcação para PTEN foi significativamente menor nos ameloblastomas do que nos germes dentários, onde PTEN foi detectado no citoplasma de tecidos odontogênicos normais e neoplásicos, sugerindo que a atividade de supressão de PTEN pode estar diminuída nos ameloblastomas. Já no estudo de Santos et al., ${ }^{18}$ foi evidenciado que ocorre uma diminuição da imunoexpressão de PTEN em germes dentários em relação aos ameloblastomas.

$\mathrm{Na}$ presente pesquisa, não se evidenciou correlação estatisticamente significante entre as imunoexpressões e os histoscores de PI3K e PTEN nos ameloblastomas, o que pode sugerir o envolvimento de outros mecanismos celulares associados com a via PI3K/PTEN. No estudo de Hendarmin et al., ${ }^{19}$ foi evidenciado que o fator de necrose tumoral alfa (TNF $\alpha$ ) mostrou ser expresso em células de ameloblastoma e que este pode induzir AKT e ativar MAPK através de PI3K, permitindo proliferação celular e sobrevivência.

$\mathrm{Yu}$ et al. $^{20}$ evidenciaram em estudo com cultura de células de câncer colorretal (CCR) que uma proteína de matriz denominada ODAM (Proteína associada ao ameloblasto odontogênico) está diretamente associada ao aumento de PTEN, revelando a natureza regulatória 
posistiva da proteína de origem dentária e a via PI3K/PTEN. Ao associar esses eventos com os achados do presente estudo, sugere-se que ODAM pode estar relacionada com ativação da via PI3K/AKT em ameloblastomas.

Scheper et al. ${ }^{6}$ identificaram que os folículos dentários apresentaram expressão positiva de PTEN em todos os casos e que em comparação com os ameloblastomas, os folículos dentários mostraram maiores níveis de expressões médias para PTEN. Além disso, PTEN esteve presente em apenas 66,7\% dos casos de ameloblastomas, diferindo do presente estudo onde a imunoexpressão de PTEN ocorreu em todas as amostras de ameloblastomas. Entretanto, outros mecanismos moleculares podem inativar a ação de PTEN, como a perda de heterozigosidade.

Nodit et al. $^{21}$ analisaram a perda de heterozigosidade em ameloblastomas, sendo 08 convencionais, 02 unicísticos, 02 ameloblastomas periféricos e 03 carcinomas ameloblásticos. Os resultados indicaram que existe uma frequência relativamente alta de perda alélica em tumores ameloblásticos (frequência de $47 \%$ de perda alélica) e ao comparar as taxas de perda alélica entre diferentes tipos de tumores, foi evidenciada uma maior taxa nos tumores unicísticos (67 vs 43\%). Além disso, a maioria das perdas alélicas ocorreu no gene $L-M Y C$ (71\%) e no gene PTEN (62\%). No presente estudo, a expressão imunohistoquímica nuclear de PTEN foi elevada tanto nos ameloblastomas convencionais $(92,96 \pm 2,58)$, quanto nos unicísticos $(94,24 \pm 4,49)$. Além disso, houve elevada imunoexpressão citoplasmática nos ameloblastomas convencionais $(98,60 \pm 0,89)$ e nos unicísticos $(100,00 \pm 0,00)$, evidenciando que a imunomarcação elevada ocorre independente do comportamento clínico do AM.

A comparação entre os grupos de $\mathrm{OKC}$ e $\mathrm{AM}$ evidenciaram uma maior imunoexpressão nuclear e citoplasmática de PTEN em AM do que em $\mathrm{OKC}$, isso pode estar associado à tentativa de supressão da via PI3K/PTEN nos AM, uma vez que a maior imunoexpressão de PTEN em AM possa indicar que ocorra uma inativação funcional de PTEN nesse tumor, podendo sua função supressora tumoral estar comprometida. Chaisuparat et al. ${ }^{7}$ evidenciaram uma maior imunoexpressão de p-AKT (Thr308) em AM (73\%) do que nos OKC (40\%). Isso pode sugerir que a via pode estar envolvida com a patogênese e o desenvolvimento dessas lesões.

Já a correlação negativa entre a imunoexpressão citoplasmática de PI3K e PTEN nos OKC $(\mathrm{p}=0,019)$ pode elucidar uma ativação da via nessas lesões, uma vez que a presença de PI3K e PTEN no citoplasma ocorre de maneira oposta, independente da intensidade. No estudo de Chaisuparat et al., ${ }^{7}$ foi evidenciada nos OKC uma elevada expressão de p-PS6K, um produto final da ativação da via PI3K/AKT/mTOR, assim como na presente pesquisa foi evidenciada uma elevada porcentagem de imunoexpressão de PI3K e uma menor imunoexpressão de PTEN nos $\mathrm{OKC}$, sugerindo também que a via está ativa nessas lesões. Esses eventos podem se 
correlacionar com o perfil de crescimento dos $\mathrm{OKC}$, uma vez que o aumento da atividade da proteína p-PS6K leva a um aumento na síntese proteica e na proliferação celular e que a maior imunoexpressão de PI3K em relação ao PTEN pode indicar o envolvimento de fatores de crescimento na ativação da via. Contudo, devido à escassez de trabalhos que avaliem a presença de PI3K e por este estudo ser o primeiro a investigar a imunoexpressão de PTEN em ceratocistos odontogênicos, necessita-se de novos estudos que busquem elucidar o real papel destas proteínas na patogênese dessa lesão.

\section{CONCLUSÕES}

Diante dos resultados obtidos nesta pesquisa, pode-se concluir que PI3K e PTEN estão presentes nos constituintes epiteliais de OKC e de AM, evidenciando-se uma maior imunoexpressão nuclear e citoplasmática de PTEN nos AM do que OKC. Além disso, existe uma correlação significante entre a imunoexpressão citoplasmática de PI3K e PTEN em OKC, sugerindo que a via pode estar ativa nessas lesões. Novos estudos são necessários para melhor elucidar o papel dessas proteínas na patogênese e no desenvolvimento dos ceratocistos odontogênicos e ameloblastomas.

\section{COLABORADORES}

Filipe Nobre Chaves, Ealber Macedo Luna, Thaís Torres, Paulo Goberlânio Barros Silva, Alceu Machado de Sousa e Débora Rejane Alves Cavalcante participaram no suporte técnico nas fases laboratoriais da pesquisa.

\section{AGRADECIMENTOS}

Ao Pró-Ensino na Saúde, por meio da Coordenação de Aperfeiçoamento de Nível Superior (CAPES), pela concessão da bolsa de mestrado.

\section{REFERÊNCIAS}

1. Lo Muzio L, Mascitti M, Santarelli A, Rubini C, Bambini F, Procaccini M. et al. Cystic lesions of the jaws: a retrospective clinicopathologic study of 2030 cases. Oral and Maxillofacial Surgery, p. 1-11, 2017.

2. El-Naggar AK, Chan JKC, Grandis JR, Takata T, Slootweg PJ, WHO Classification of Head and Neck Tumours (4th edition). IARC: Lyon, 2017.

3. Porta C, Paglino C, Mosca A. Targeting PI3K/Akt/mTOR Signaling in. Cancer Front Oncol. 2014.

4. Engelman JA. Targeting PI3K signalling in cancer: opportunities, challenges and limitations. Nat Rev Cancer. 2009;9:550-562. 
5. Ettl T, Schwarz FS, Haubner F, Müller S, Zenk J, Gosau M, Reichert TE, Zeitler K. The $\mathrm{PI} 3 \mathrm{~K} / \mathrm{AKT} / \mathrm{mTOR}$ signalling pathway is active in salivary gland cancer and implies different functions and prognoses depending on cell localisation.Oral Oncol. 2012.

6. Scheper MA, Chaisuparat R, Nikitakis NG, Sauk JJ. Expression and alterations of the PTEN AKT/mTOR pathway in ameloblastomas. Oral Diseases, v.14, p.561-568, 2008.

7. Chaisuparat R, Yodsanga S, Montaner S, Jham BC. Activation of the Akt/mTOR pathway in dentigerous cysts, odontogenic keratocysts, and ameloblastomas. Oral and Maxillofacial Pathology. v. 116, n. 3, p.336-342, 2013.

8. Hormozi E, Vahid Nourollahi Fard, [...], and Forooz Keshani. Comparison of immunohistochemical expression of CD10 in keratocystic odontogenic tumor and ameloblastoma. Dent Res J (Isfahan), v.13, n.2, p.110-116. 2016.

9. Antunes AA, Avelar RL, Thiago de Santana Santos, Andrade ESS, Dourado E.Tumor Odontogênico Ceratocistico: análise de 69 casos. Rev. Bras. Cir. Cabeça Pescoço. v. 36, n. 2: p.80-82, 2007.

10. Güler N, Sençift K, Demirkol O. Conservative Management of Keratocystic Odontogenic Tumors of Jaws. Scientific World Journal. 2012.

11. Gaballah ETMA, Tawfik MA. Immunohistochemical analysis of p53 protein in odontogenic cysts. The Saudi Dental Journal, v. 22, p.167-170. 2010.

12. Jamshidi Sh., Zargaran M, Nazhvani AD. Immunohistochemical Comparison of the Expression of CD34 and CD105 in Odontogenic Keratocyst and Dentigerous Cyst. $J$ Dent Shiraz Univ Med Sci., v.18, n.1, p: 43-49. 2017.

13. Hertog D, Bloemena E, [...], Van-der-Waal I. Histopathology of ameloblastoma of the jaws; some critical observations based on a 40 years single institution experience. Med Oral Patol Oral Cir Bucal. 2012 Jan 1;17 (1):e76-82.

14. Milman T, Ying GS, Pan W, LiVolsi V. Ameloblastoma: 25 Year Experience at a Single Institution. Head and Neck Pathol, 10:513-520, (2016).

15. Kurppa KJ, Catón J, Morgan PR, Ristimäki A, Ruhin B, Kellokoski J, Elenius K, Heikinheimo K. High frequency of BRAF V600E mutations in ameloblastoma. Journal of Pathology, 2014; 232: 492-498.

16. Hu S, Divaris K, Parker J, Padilla R, Murrah V, Wright VT. Transcriptome Variability in Keratocystic Odontogenic Tumor Suggests Distinct Molecular Subtypes. Nature.com/scientificreports, 2016.

17. Kumamoto H, Ooya K. Immunohistochemical detection of phosphorylated Akt, PI3K, and PTEN in ameloblastic tumors. Oral Diseases, v.13, p.461-467, 2007.

18. Santos SEM, Santos HO, [...], and Farias LC. Bioinformatics Analysis Reveals Genes Involved in the Pathogenesis of Ameloblastoma and Keratocystic Odontogenic Tumor. Int J Mol Cell Med Autumn, v.5, n.4, 2016.

19. Hendarmin L, Sandra F, Nakao Y, Ohishi M, Nakamura N. TNFalpha played a role in induction of Akt and MAPK signals in ameloblastoma. Oral Oncol, 2005, v. 41, n.4, $\mathrm{p}: 375-82$.

20. Yu M, Mu Y, Qi Y, Qin S, Qiu Y, Cui R, Zhong M. Odontogenic ameloblast-associated protein (ODAM) inhibits human colorectal cancer growth by promoting PTEN elevation and inactivating PI3K/AKT signaling.Biomed Pharmacother. 2016.

21. Nodit L, Barnes L, Childers E, Finkelstein S, Swalsky P, Hunt J. Allelic loss of tumor suppressor genes in ameloblastic tumors. Modern Pathology, v.17, p.1062 -1067. 2004. 


\section{FIGURAS}

\section{PI3K}

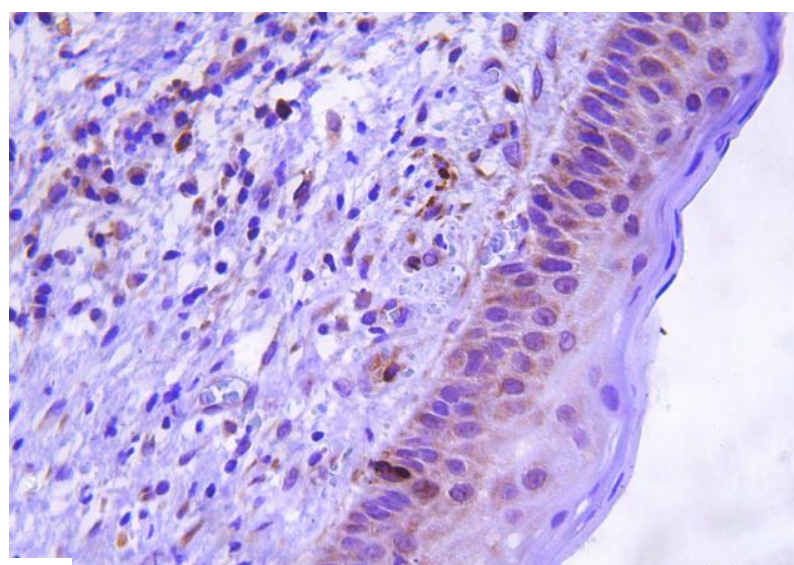

\section{PTEN}

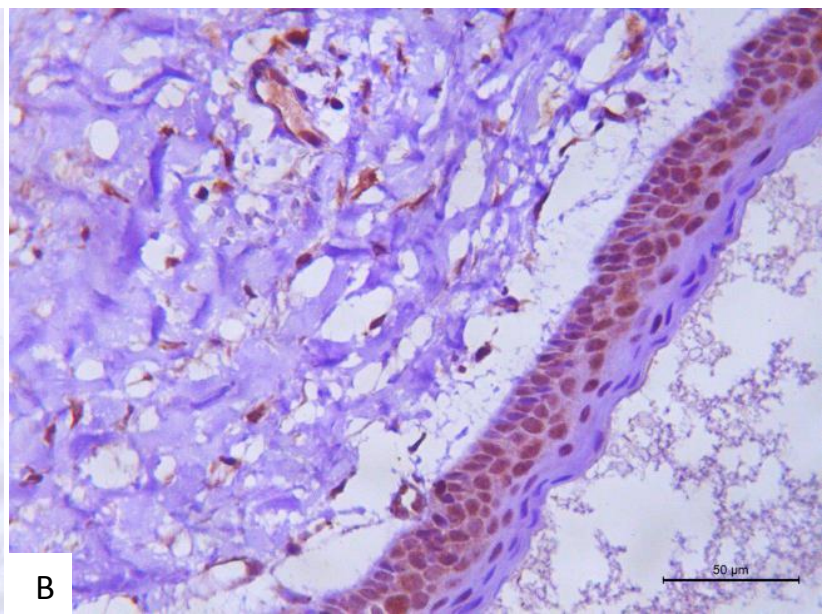

A
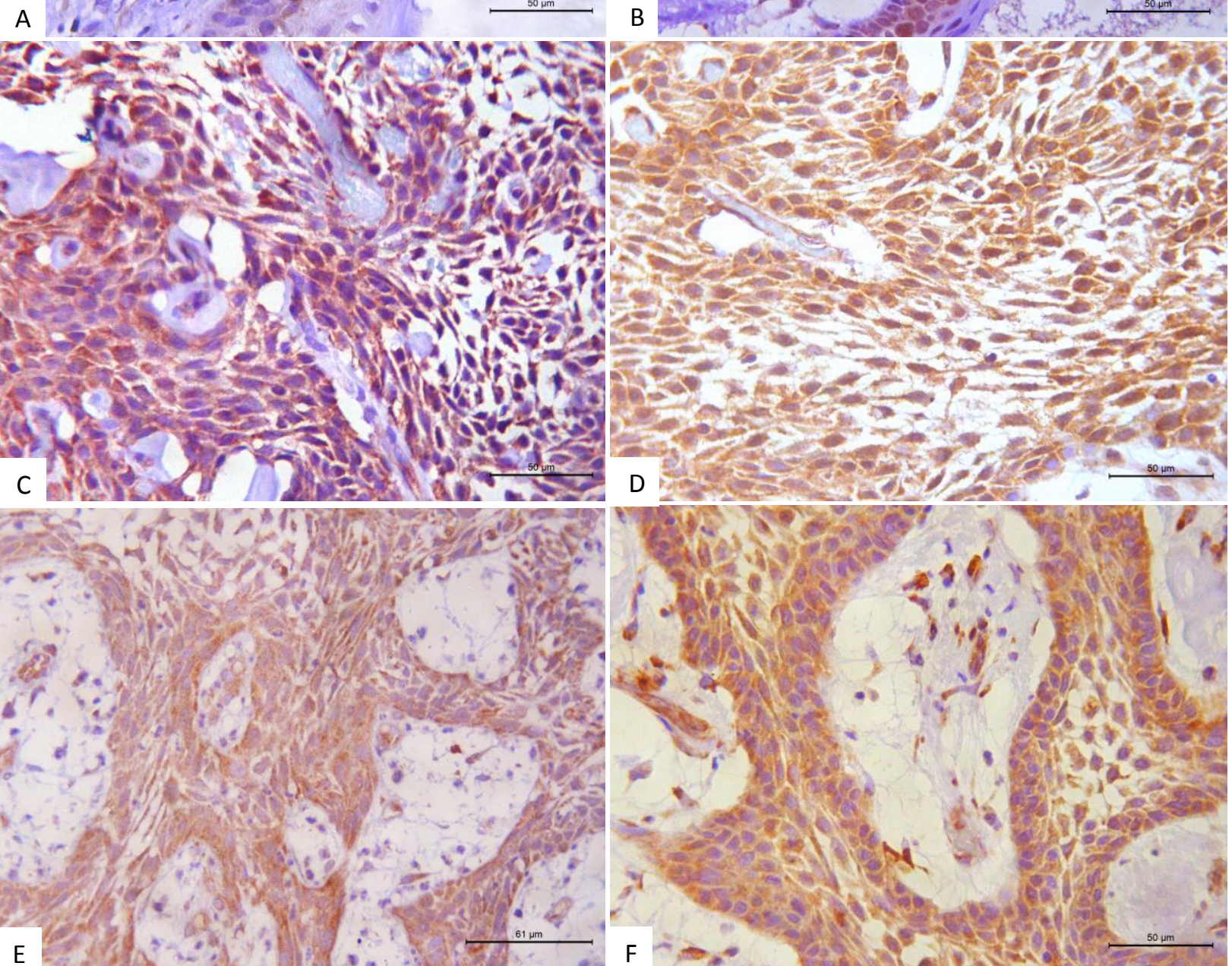

Figura 1. A) Fotomicrografia exibindo imunoexpressão citoplasmática e membranar de PI3K no revestimento epitelial de OKC. B) Fotomicrografia exibindo imunoexpressão nuclear e citoplasmática de PTEN no revestimento epitelial de OKC. C) Fotomicrografia exibindo imunoexpressão citoplasmática e membranar de PI3K em AM unicístico. D) Fotomicrografia exibindo imunoexpressão nuclear e citoplasmática de PTEN em AM unicístico. E) Fotomicrografia exibindo imunoexpressão citoplasmática e membranar de PI3K em AM convencional. F) Fotomicrografia exibindo imunoexpressão nuclear e citoplasmática de PTEN em AM convencional (LSAB, 400x). 


\section{TABELAS}

Tabela 1- Perfil Epidemiológico da Amostra.

\begin{tabular}{|c|c|c|c|c|c|c|c|}
\hline & \multicolumn{2}{|c|}{ Ameloblastoma } & \multirow{2}{*}{$\begin{array}{c}\text { p- } \\
\text { Valor }\end{array}$} & \multirow[b]{2}{*}{ Ceratocisto } & Lesão & \multirow{2}{*}{$\begin{array}{c}\text { p- } \\
\text { Valor }\end{array}$} & \multirow[b]{2}{*}{ Total } \\
\hline & Convencional & Unicístico & & & Ameloblastoma & & \\
\hline \multicolumn{8}{|l|}{ Sexo } \\
\hline Feminino & 4 & 2 & 0,524 & 7 & 6 & 1,000 & 13 \\
\hline Masculino & 1 & 3 & & 3 & 4 & & 7 \\
\hline \multicolumn{8}{|l|}{ Idade } \\
\hline Até 20 & 1 & 1 & 1,000 & $8^{*}$ & 2 & 0,023 & 10 \\
\hline Mais de 20 anos & 4 & 4 & & 2 & $8^{*}$ & & 10 \\
\hline \multicolumn{8}{|l|}{ Localização } \\
\hline Maxila & 0 & 1 & 0,117 & 1 & 1 & 0,871 & 2 \\
\hline $\begin{array}{l}\text { Anterior de } \\
\text { mandíbula }\end{array}$ & 0 & 2 & & 3 & 2 & & 5 \\
\hline $\begin{array}{l}\text { Posterior de } \\
\text { mandíbula }\end{array}$ & 5 & 2 & & 6 & 7 & & 13 \\
\hline
\end{tabular}

$* \mathrm{p}<0,05$ teste exato de Fisher ou qui-quadrado de Pearson (dados expressos em forma de número de casos) 
Tabela 2 - Porcentagens e histoscore de células imunomarcadas entre ceratocistos odontogênicos e ameloblastomas.

\begin{tabular}{lccc}
\hline & \multicolumn{2}{c}{ Lesões odontogênicas } & \\
\cline { 2 - 3 } & $\begin{array}{c}\text { Ceratocisto } \\
\text { odontogênico }\end{array}$ & Ameloblastoma & p-Valor \\
\hline PTEN & & & \\
\% Núcleo & $39,21 \pm 12,38$ & $93,60 \pm 2,45$ & $<\mathbf{0 , 0 0 1}$ \\
\% Citoplasma & $87,35 \pm 5,72$ & $99,30 \pm 0,48$ & $\mathbf{0 , 0 2 3}$ \\
Histoscore Núcleo & $4,90 \pm 1,36$ & $11,20 \pm 0,53$ & $\mathbf{0 , 0 0 3}$ \\
Histoscore Citoplasma & $7,30 \pm 1,08$ & $11,20 \pm 0,53$ & $\mathbf{0 , 0 1 1}$ \\
PI3K & & & \\
\% Membrana & $88,88 \pm 4,91$ & $86,67 \pm 4,07$ & 0,280 \\
\% Citoplasma & $99,72 \pm 0,05$ & $99,39 \pm 0,20$ & 0,315 \\
Histoscore Membrana & $7,10 \pm 0,85$ & $5,60 \pm 0,70$ & 0,247 \\
Histoscore Citoplasma & $7,20 \pm 0,80$ & $6,00 \pm 0,67$ & 0,353 \\
\hline
\end{tabular}

${ }^{*} \mathrm{p}<0,05$, Teste Mann-Whitney (Média \pm EPM). 
Tabela 3 - Porcentagens e histoscore de células imunomarcadas entre as variantes clínicas de ameloblastoma.

\begin{tabular}{lccc}
\hline & \multicolumn{2}{c}{ Ameloblastoma } & \\
\cline { 2 - 3 } & $\begin{array}{c}\text { Ameloblastoma } \\
\text { unicístico }\end{array}$ & $\begin{array}{c}\text { Ameloblastoma } \\
\text { convencinal }\end{array}$ & p-Valor \\
\hline PTEN & $94,24 \pm 4,49$ & $92,96 \pm 2,58$ & 0,421 \\
\% Núcleo & $100,00 \pm 0,00$ & $98,60 \pm 0,89$ & 0,310 \\
\% Citoplasma & $12,00 \pm 0,00$ & $10,40 \pm 0,98$ & 0,310 \\
Histoscore Núcleo & $12,00 \pm 0,00$ & $10,40 \pm 0,98$ & 0,310 \\
Histoscore Citoplasma & & & \\
PI3K & $80,76 \pm 7,25$ & $92,58 \pm 2,08$ & 0,421 \\
\% Membrana & $99,00 \pm 0,30$ & $99,78 \pm 0,07$ & 0,064 \\
\% Citoplasma & $5,60 \pm 1,12$ & $5,60 \pm 0,98$ & 0,841 \\
Histoscore Membrana & $6,40 \pm 0,98$ & $5,60 \pm 0,98$ & 0,690 \\
Histoscore Citoplasma & & & \\
\hline *p<0,05, Teste Mann-Whitney (Média \pm EPM). & & \\
\hline
\end{tabular}


Tabela 4 - Correlação entre a imunoexpressão de PI3K e PTEN nos ceratocistos odontogênicos e ameloblastomas.

\begin{tabular}{|c|c|c|c|c|c|}
\hline \multirow[b]{3}{*}{ PTEN } & & \multicolumn{4}{|c|}{ PI3K } \\
\hline & & $\%$ & $\%$ & Histoscore & Histoscore \\
\hline & & Membrana & Citoplasma & Membrana & Citoplasma \\
\hline \multicolumn{6}{|l|}{ Ceratocisto odontogênico } \\
\hline \multirow[t]{2}{*}{ \% Núcleo } & $\mathbf{R}$ & $-0,251$ & $-0,426$ & 0,007 & $-0,007$ \\
\hline & p-Valor & 0,485 & 0,220 & 0,985 & 0,985 \\
\hline \multirow[t]{2}{*}{$\%$ Citoplasma } & $\mathbf{R}$ & 0,179 & $-0,721^{*}$ & 0,284 & 0,274 \\
\hline & p-Valor & 0,621 & 0,019 & 0,426 & 0,444 \\
\hline \multirow[t]{2}{*}{ Histoscore Núcleo } & $\mathbf{R}$ & $-0,126$ & $-0,479$ & 0,124 & 0,107 \\
\hline & p-Valor & 0,729 & 0,161 & 0,733 & 0,768 \\
\hline \multirow[t]{2}{*}{ Histoscore Citoplasma } & $\mathbf{R}$ & $-0,101$ & $-0,444$ & 0,015 & 0,026 \\
\hline & p-Valor & 0,781 & 0,198 & 0,968 & 0,943 \\
\hline \multicolumn{6}{|l|}{ Ameloblastoma } \\
\hline \multirow[t]{2}{*}{$\%$ Núcleo } & $\mathbf{R}$ & $-0,575$ & 0,076 & $-0,446$ & $-0,323$ \\
\hline & p-Valor & 0,082 & 0,835 & 0,196 & 0,362 \\
\hline \multirow[t]{2}{*}{$\%$ Citoplasma } & $\mathbf{R}$ & $-0,467$ & $-0,170$ & $-0,177$ & $-0,050$ \\
\hline & p-Valor & 0,173 & 0,638 & 0,625 & 0,892 \\
\hline \multirow[t]{2}{*}{ Histoscore Núcleo } & $\mathbf{R}$ & $-0,435$ & $-0,220$ & $-0,137$ & 0,000 \\
\hline & p-Valor & 0,209 & 0,542 & 0,706 & 1,000 \\
\hline \multirow[t]{2}{*}{ Histoscore Citoplasma } & $\mathbf{R}$ & $-0,435$ & $-0,220$ & $-0,137$ & 0,000 \\
\hline & p-Valor & 0,209 & 0,542 & 0,706 & 1,000 \\
\hline
\end{tabular}

$* \mathrm{p}<0,05$, correlação de Spearman. 


\section{CONCLUSÃO GERAL}

O perfil epidemiológico dos casos abordados na referente pesquisa evidenciou que o grupo de OKC apresentou para faixa etária de até 20 anos uma diferença estatística significante em relação ao grupo de ameloblastomas, assim como no grupo de ameloblastomas acima de 20 anos em relação aos $\mathrm{OKC}$.

Quanto à análise da imunoexpressão, os resultados do presente estudo evidenciaram que PI3K e PTEN estão presentes no epitélio de revestimento tanto dos $\mathrm{OKC}$, quanto dos $\mathrm{AM}$, pois foi observado imunomarcação em todos os casos da amostra, sendo observada uma maior imunoexpressão citoplasmática e nuclear de PTEN nos AM do que nos OKC.

A comparação entre o histoscore núcleo de PTEN nos OKC $(4,90 \pm 1,36)$ e nos casos de AM $(11,20 \pm 0,53)$ apresentou significância estatística $(\mathrm{p}=0,003)$, sendo evidenciado também significância estatística na comparação do histoscore citoplasma $(p=0,011)$ entre os OKC $(7,30 \pm 1,08)$ e os $\mathrm{AM}(11,20 \pm 0,53)$.

A correlação entre as porcentagens de imunomarcação citoplasmática de PI3K e PTEN nos grupos de OKC $(-0,721)$ evidenciou uma relação estatisticamente significante $(\mathrm{p}=0,019)$. Isso pode sugerir que a via $\mathrm{PI} 3 \mathrm{~K} / \mathrm{PTEN}$ pode estar ativa nos $\mathrm{OKC}$, em virtude da correlação negativa evidenciada se relacionar com a atividade dessas proteínas. A partir dos achados da presente pesquisa, sugere-se a realização de novos estudos para melhor elucidar o papel desenvolvido pelas proteínas PI3K e PTEN nos cistos e tumores odontogênicos. 


\section{REFERÊNCIAS}

AGARAM, N.P. et al. Molecular analysis to demonstrate that odontogenic keratocysts are neoplastic. Arch Pathol Lab Med. v.128, p.313-7, 2004.

ALYASIRI, N.S. et al. PTEN-mediated AKT activation contributes to the reduced apoptosis among Indian oral squamous cell carcinoma patients. J Cancer Res Clin Oncol. v.138, n.1, p.103-9, 2012.

ANGADI, P.V.; KRISHNAPILLAI, R. Evaluation of PTEN Immunoexpression in Oral Submucous Fibrosis: Role in Pathogenesis and Malignant Transformation. Head Neck Pathol. v.6, n.3, p.314-21, 2012.

ANTUNES, A. A. et al. Tumor Odontogênico Ceratocistico: análise de 69 casos. Rev. Bras. Cir. Cabeça Pescoço. v. 36, n. 2: p.80-82, 2007.

AVELAR, R.L. et al. Odontogenic cysts: a clinicopathological study of 507 cases. J Oral Sci. v. 51, p. 581-586, 2009.

BARNES L, EVERSON J, REICHART P. World Health Organization Classification of Tumours Pathology and Genetics of Tumours of the Head and Neck. Lyon, International Agency for Research on Cancer, 2005.

BONFITO, VL. Estudo da angiogênese em carcinomas salivares: correlação com o tipo e grau histológicos, progressão tumoral e expressão de proteínas relacionadas ao metabolismo celular. 2010.94f. Tese (Doutorado em Ciências Médicas) - Unicamp, Campinas, 2010.

BRANDT FILHO, S. H. O. et al. Decompression technique to surgical treatment of the oral cavity cysts. Revista de odontologia (São Paulo. Online), v.8, n.1, p. 525-537, 2010.

BUCHNER A, MERRELL PW, CARPENTER WM. Relative frequency of central odontogenic tumors: a study of 1,088 cases from Northern California and comparison to studies from other parts of the world. J Oral Maxillofac Surg, v.64, n.9, p:1343-52, 2006.

CAVALCANTI, M.G.P. et al. Squamous-cell carcinoma arising from an odontogenic cyst -The importance of computed tomography in the diagnosis of malignancy. Oral Surgery, Oral Medicine, Oral Pathology, Oral Radiology, and Endodontology. v. 100, n.3, p.365-368, 2005.

CEDIN, A. C. et al. Endoscopic treatment of odontogenic cyst with intra-sinusal extension. Rev. Bras. Otorrinolaringol, v.71, n.3, p.392-395, 2005.

CHAISUPARAT, R. et al. Activation of the Akt/mTOR pathway in dentigerous cysts, odontogenic keratocysts, and ameloblastomas. Oral and Maxillofacial Pathology. v. 116, n. 3, p.336-342, 2013. 
CHAISUPARAT, R. et al. Primary intraosseous odontogenic carcinoma arising in an odontogenic cyst or de novo: a clinicopathologic study of six new cases. Oral Surg Oral Med Oral Pathol Oral Radiol Endod., v. 101, n.2, p. 194-200, 2006.

CHIA, S. et al. Novel agents and associated toxicities of inhibitors of the pi3k/Akt/mtor pathway for the treatment of breast câncer. Curr Oncol, v. 22, p. 33-48, 2015.

CHOI, K.K. et al. Independente prognostic factors of 861 cases of oral squamous cell carcinoma in Korean adults. Oral Oncol. v. 42, n. 2, p. 208-217, 2006.

COLIC, M. et al. Proinflammatory and immunoregulatory mechanisms in periapical lesions.

Mol. Immunol. v.47, n.1, p. 101-113, 2009.

COSTA, F.R.; ESTEVES, C.; BACELAR, M.T. Lesões benignas da mandíbula: uma revisão pictórica. Acta Radiológica Portuguesa, v.28, n.108, p.25-35, 2016.

CUNHA, J.F. et al. Clinicopathologic features associated with recurrence of the odontogenic keratocyst: a cohort retrospective analysis. Oral Surg Oral Med Oral Pathol Oral Radiol. v.121, n. 6, 2016.

DAHIA, P.L.M. PTEN, a unique tumor suppressor gene. Endocr Relat Cancer., v.7, n.2, p.115$129,2000$.

DALEY, T.D.; WYSOCKI, G.P.; PRINGLE G.A. Relative incidence of odontogenic tumors and oral jaw cysts in a Canadian population. Oral Surg Oral Med Oral.v.77, n.3, p. 276-280, 1994.

DEBONI, M. C. Z. et al. Surgical management of dentigerous cyst and keratocystic odontogenic tumor in children: a conservative approach and 7-year follow-up. J Appl Oral Sci. v. 20, n. 2, p. 268-271, 2012.

DE OLIVEIRA, M.G. et al. Immunohistochemical analysis of the patterns of p53

and PCNA expression in odontogenic cystic lesions. Med Oral Patol Oral Cir Bucal. v.1, n.13, p.275-80, 2008.

DE PAULA, A M. et al. Cell proliferation markers in the odontogenic keratocyst: effect of inflammation. J Oral Pathol Med. n.29, v.10, p: 477-82, 2000.

DE VICENTE, J.C. et al. Immunohistochemical comparative study of the odontogenic keratocysts and other odontogenic lesions. Med Oral Patol Oral Cir Bucal. v.15, n.5, p.709$715,2010$.

ENGELMAN, J.A. Targeting PI3K signalling in cancer: opportunities, challenges and limitations. Nat Rev Cancer. v.9, p.550-562, 2009.

EL NAGGAR, A. K. et al. WHO Classification of Head and Neck Tumours (4th edition). IARC: Lyon, 2017. 
ETTL T. et al. The PI3K/AKT/mTOR signalling pathway is active in salivary gland cancer and implies different functions and prognoses depending on cell localisation.Oral Oncol. 2012.

FRESNO VARA, J.A. et al. PI3K/Akt signalling pathway and cancer. Cancer Treat Rev., v.30, n.2, p.193-204, 2004.

GABALLAH, E.T.M.A., TAWFIK, M.A. Immunohistochemical analysis of p53 protein in odontogenic cysts. The Saudi Dental Journal, v. 22, p.167-170. 2010.

GADBAIL, A. R.; PATIL, R.; CHAUDHARY, M. Coexpression of Ki-67 and p53 protein in ameloblastoma and keratocystic odontogenic tumor. Acta Odontol Scand, 2011.

GIUDICE, F.S.; SQUARIZE, C.H. The determinants of head and neck cancer: Unmasking the PI3K pathway mutations. J Carcinog Mutagen. Suppl 5, 2014.

GONZALEZ, E.; MCGRAW, T.E. The Akt kinases: isoform specificity in metabolism and cancer. Cell Cycle., v.8, n.16, p.2502-2508, 2009.

GRIMM, M. et al. Association of cancer metabolism-related proteins with oral carcinogenesis indications for chemoprevention and metabolic sensitizing of oral squamous cell carcinoma? $\mathbf{J}$ Transl Med. v.12, n.6, p. 165-169, 2014.

GÜLER N, SENÇIFT K, DEMIRKOL O. Conservative Management of Keratocystic Odontogenic Tumors of Jaws. Scientific World Journal. 2012.

HAYASHITA, Y.H. et al. A polycistronic microRNA cluster, miR-17-92, is overexpressed in human lung cancers and enhancers cell proliferation. Cancer Res, v.65, n.21, p.9628-9632, 2005 .

HENDARMIN, L. et al.. TNFalpha played a role in induction of Akt and MAPK signals in ameloblastoma. Oral Oncol, v. 41, n.4, p:375-82. 2005.

HENLEY, J. et al. Summerlin DJ, Tomich C, Zhang S, Cheng L. Molecular evidence supporting the neoplastic nature of odontogenic keratocyst: a laser capture microdissection study of 15 cases . Histopathology, v.47, p.582-6, 2005.

HERTOG, D. et al. Histopathology ofameloblastoma of the jaws; some critical observations based on a 40 years single institution experience. Med Oral Patol Oral Cir Bucal, v.17, n.1, p.e76-82, 2012.

HORMOZI, E. et al. Comparison of immunohistochemical expression of CD10 in keratocystic odontogenic tumor and ameloblastoma. Dent Res J (Isfahan), v.13, n.2, p.110-116, 2016.

HU, S. et al. Transcriptome Variability in Keratocystic Odontogenic Tumor Suggests Distinct Molecular Subtypes. Nature.com/scientificreports, 2016.

HUANG, B.X. et al. Phosphatidylserine is a critical modulator for Akt activation. J Cell Biol., v.192, n.6, p.979-992, 2011. 
IORIO, M.V. et al. MicroRNA gene expression deregulation in human breast cancer. Nature, n.353, p.184-187, 2005.

JAMSHIDI, S.H. et al. Immunohistochemical Comparison of the Expression of CD34 and CD105 in Odontogenic Keratocyst and Dentigerous Cyst. J Dent Shiraz Univ Med Sci., v.18, n.1, p: 43-49. 2017.

KOMINSKY, D.J. ; CAMPBELL, E.L.;COLGAN, S.P. Metabolic shifts and immunity and inflammation. J. Imunnol. v. 184. p. 4062-4068, 2010.

KUMAMOTO, H.; OOYA, K. Immunohistochemical detection of phosphorylated Akt, PI3K, and PTEN in ameloblastic tumors. Oral Diseases, v.13, p.461-467, 2007.

KURPPA, K. J.et al. High frequency of BRAFV600E mutations in ameloblastoma. J Pathol. v.232, n.5, p:492-498. 2014.

LI, N. et al. Expression of phosphorylated Akt/mTOR and clinical significance in human ameloblastoma. Int J Clin Exp Med, v.8, n.4, p.5236-5244, 2015.

LIMA, G.M.; NOGUEIRA, R.L.M.; RABENHORST, S.H.B. Detection of the p53 Protein in Odontogenic Cysts and Unicystic Ameloblastoma. Rev. Cir. Traumatol. Buco-Maxilo-Fac., v.6, n.1, p. 47 - 54, 2006.

LO MUZIO, L. et al. Cystic lesions of the jaws: a retrospective clinicopathologic study of 2030 cases. Oral and Maxillofacial Surgery, p. 1-11, 2017.

MADHUNAPANTULA S.V.; ROBERTSON, G.P. The PTEN-AKT3 signaling cascade as a therapeutic target in melanoma. Pigment Cell Melanoma Res., v.22, n.4, p.400- 419, 2009.

MADHUNAPANTULA, S.V. et al. The Akt signaling pathway: an emerging therapeutic target in malignant melanoma.. Review article. Cancer Biol Ther. 2011

MALCIC, A. et al. Alterations of FH IT and P53 genes in keratocystic odontogenic tumour, dentigerous cyst and radicular cyst. Journal of Oral Pathology and Medicine, n.37, p.294-301, 2008 .

MALLMANN, C.T. et al. Tumor odontogênico ceratocístico - levan tamento de casos e revisão de literatura. Odonto, v.20(40): 67-72. 2012.

MARTINS, F. et al. PI3K-AKT-mTOR pathway proteins are differently expressed in oral carcinogenesis. J Oral Pathol Med, v.45, p.746-752, 2016.

MATOS, F.R. et al. Expression of MMPs, angiogenic and proliferation cell markers in odontogenic tumors. J Bras Patol Med Lab, v. 48, n. 5, p. 375-381, 2012.

MENON, S. Keratocystic Odontogenic Tumours: Etiology, Pathogenesis and Treatment Revisited. J. Maxillofac. Oral Surg. v.14, n.3, p.541-547, 2015. 
MILMAN, T. et al. Ameloblastoma: 25 Year Experience at a Single Institution. Head and Neck Pathol, v.10, p.513-520, 2016.

MITROU, G.K. et al. Odontogenic keratocyst expresses vascular endotelial growth factor: an immunohistochemical study. J Oral Pathol Med, v.38, p.470-475, 2009.

MYOUNG, H. et al. Odontogenic Keratocyst: review of 256 cases for recurrence and clinicopathologic parameters. Oral Sur Oral MedOral Pathol Oral Radiol \& Endod, v. 91, n. 3, p. 328-333, 2001.

MOSQUEDA,T. et al. Odontogenic cysts: analysis of 856 cases. Med Oral. V.7, P. 89-96, 2002.

MUKOHARA, Toru. PI3K mutations in breast cancer: prognostic and therapeutic implications. Breast Cancer (Dove Med Press). 2015; 7: 111-123.

NAGI R, SAHU S, RAKESH N. Molecular and genetic aspects in the etiopathogenesis of ameloblastoma: An update. J Oral Maxillofac Pathol. v.20, n.3, p:497-504, 2016.

NODIT, L. et al. Allelic loss of tumor suppressor genes in ameloblastic tumors. Modern Pathology (2004) 17, $1062-1067$.

OCAÑA, R. P. et al.Tratamento ExtensoTumor Odontogênico Ceratocistico por Descompressão e Complementação Cirúrgicacom Solução de Carnoy. Revista Portuguesa de Estomatologia, Medicina Dentária e Cirurgia Maxilofacial, v. 50, n.2, 2009.

PEIXOTO, R. F. etal. Odontogenic Keratocyst tumours: a Review of Current Findings. Rev. Cir. Traumatol. Buco Maxilo Fac,v.9, n.3: p.21-28, 2009.

PHILIPSEN, H.P. Om keratocyster (kolesteatom) I kaeberbe. Tandlaegebladet, v.60:963-80, 1956.

PORTA, C.; PAGLINO, C; MOSCA, A. Targeting PI3K/Akt/mTOR Signaling in Cancer. Front Oncol. 2014.

SANDULACHE, V.C.; MYERS, J.N. Altered metabolism in head and neck squamous cell carcinoma: an opportunity for identification of novel biomarkers and drug targets. Head Neck. v. 34, p. 282-290, 2012.

SANTOS, E M S et al. Bioinformatics Analysis Reveals Genes Involved in the Pathogenesis of Ameloblastoma and Keratocystic Odontogenic Tumor. Int J Mol Cell Med Autumn, v.5, n.4, 2016.

SANTOS, T. S. et al. Odontogenic cysts: epidemiological study of 72 cases. Rev. Bras. Cir. Cabeça Pescoço, São Paulo, v.36, n.1, p.30-32, 2007.

SCHEPER M.A. et al. Expression and alterations of the PTEN AKT $/ \mathrm{mTOR}$ pathway in ameloblastomas. Oral Diseases, v.14, 561-568, 2008.

SHEAR, M; SPEIGHT, P. Cistos da região bucomaxilofacial.4 ed, Editora Santos, 2011. 
SIMPSON, L.; PARSONS, R. PTEN: life as a tumor suppressor. Exp Cell Res., v.264, n.1, p.29-41, 2001.

SNIETURA, M. et al. PTEN as a Prognostic and Predictive Marker in Postoperative Radiotherapy for Squamous Cell Cancer of the Head and Neck. Plos One., v.7, n.3, p.e33396, 2012.

SONG, G.; OUYANG, G.; BAO, S. The activation of Akt/PKB signaling pathway and cell survival. J Cell Mol Med., v.9, n.1, p.59-71, 2005.

SOUZA, L.B. et al. Odontogenic cysts:demographic profile in a Brazilian population over a 38year period. Med Oral Patol Oral Cir Bucal. v. 15, n. 4, p. 583-590, 2010.

SQUARIZE, Cristiane Helena. Estudo comparativo da expressão imunoistoquímica de PTEN e da graduação histológica de malignidade em carcinomas epidermóides bucais. 72f. Dissertação (Mestrado em Odontologia) - Faculdade de Odontologia da Universidade de São Paulo, 2002.

VAROLI, F. P. et al. Tumor odontogênico queratocistico: característica intrínseca e elucidação da nova nomenclatura do queratocisto Odontogênico. Journal Heath Sci inst, v. 28, n.1, p.8083. 2010.

WANG, X.; HUANG, H.; YOUNG, K.H. The PTEN tumor suppressor gene and its role in lymphoma pathogenesis. Aging (Albany NY), n.7, v.12, p.1032-1049, 2015.

WRIGHT, J.M; VERED, M. Update from the 4th Edition of the World Health Organization Classification of Head and Neck Tumours: Odontogenic and Maxillofacial Bone Tumours. Head and Neck Pathol, v.11, p:68-77, 2017.

YAMADA, K. M.; ARAKI, M. Tumor suppressor PTEN: modulator of cell signaling, growth, migration and apoptosis. J Cell Sci., v.114, n.13, p.2375-82, 2001.

YOSHIURA, K. et al. Cystic lesions of mandible and maxilla. Neuroimaging Clin. N. Am. v.13, n.3, p.485-494, 2003.

YU, M. et al. Odontogenic ameloblast-associated protein (ODAM) inhibits human colorectal cancer growth by promoting PTEN elevation and inactivating PI3K/AKT signaling.Biomed Pharmacother. 2016.

ZHAO, Y.et al. Recurrent Keratocystic odontogenic tumours: report of 19 cases. Dento maxillofacial Radiology, v.41, p.96-102. 2012. 


\section{ANEXO A- SEGMENTO DO REGIMENTO INTERNO}

ARTIGO 46- As dissertações apresentadas ao Programa de Pós-Graduação em Odontologia da Universidade Federal do Ceará poderão ser produzidas em formato alternativo ou tradicional. O formato alternativo estabelece: a critério do orientador e com a aprovação da Coordenação do Programa, que os capítulos e os apêndices poderão conter cópias de artigos de autoria ou co-autoria do candidato, publicados ou ainda não submetidos para publicação em periódicos científicos, escritos no idioma exigido pelo veículo de divulgação.

$\S 1^{\circ}$ - O orientador e o candidato deverão verificar junto às editoras a possibilidade de inclusão dos artigos na dissertação ou tese, em atendimento à legislação que rege o direito autoral, obtendo, se necessária, a competente autorização, devendo assinar declaração de que não estão infringindo o direito autoral transferido à editora. 


\section{UFC - UNIVERSIDADE FEDERAL DO CEARÁ /}

\section{PARECER CONSUBSTANCIADO DO CEP}

\section{DADOS DO PROJETO DE PESQUISA}

Título da Pesquisa: Avaliação da imunoexpressão do fator induzido por hipóxia-1(HIF-1) e de proteínas da via PI3KJAKT/PTEN em cistos e tumores odontogênicos.

Pesquisador: KARUZA MARIA ALVES PEREIRA

Área Temática:

Versão: 3

CAAE: 62974716.2 .0000 .5054

Instituição Proponente:Departamento de Clínica Odontológica

Patrocinador Principal: Financiamento Próprio

\section{DADOS DO PARECER}

Número do Parecer: 2.108.274

\section{Apresentação do Projeto:}

Dentre as lesōes que levam a destruição óssea nos maxilares, os cistos odontogênicos são as mais comuns. São classificados conforme com sua origem em: cistos de desenvolvimento, incluindo o cisto dentígero ou em cistos inflamatórios, como o cisto radicular. Tanto o cisto dentígero quanto o radicular podem apresentar graus variados de inflamação, sendo esta primária ou secundária. Estudos recentes sugerem que citocinas como interleucina-1 e fator de necrose tumoral-alfa liberadas durante o processo inflamatório, podem ser responsáveis pela ativação por via não-hipóxica do fator induzido por hipóxia (HIF1), este influencia nos mecanismos de adaptação celular frente as alteraçōes na concentração de oxigênio. Os tumores odontogênicos compreendem um grupo complexo de lesões de diversos tipos histopatológicos e comportamentos clínicos. Dentre estes, o tumor odontogênico ceratocístico (TOC), antes categorizado como cisto, foi reclassificado em 2005 pela Organização Mundial de Saúde como um tumor odontogênico benigno, devido seu caráter recidivante e invasivo, representando aproximadamente $11 \%$ de todas as lesōes cisticas dos maxilares. A sua patogênese apresenta controvérsias, o que limita a existência de marcadoresmoleculares de prognóstico que proporcionem uma melhor abordagem terapêutica. Umas das vias maisestudadas na tumorigênese é a PI3K/AKT/PTEN. Dentro dos cistos e tumores odontogênicos, essa via de

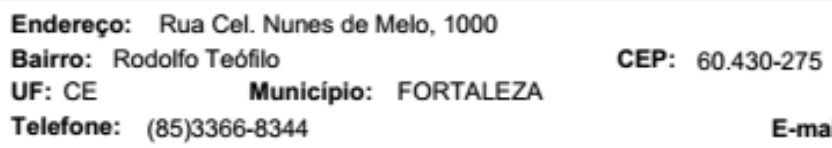




\section{UFC - UNIVERSIDADE FEDERAL DO CEARÁ /}

Continuaçâo do Parecer: 2.108.274

\section{Recomendações:}

Não se aplica.

Conclusões ou Pendências e Lista de Inadequações:

Não se aplica.

Considerações Finais a critério do CEP:

Este parecer foi elaborado baseado nos documentos abaixo relacionados:

\begin{tabular}{|c|c|c|c|c|}
\hline Tipo Documento & Arquivo & Postagem & Autor & Situação \\
\hline $\begin{array}{l}\text { Informaçōes Básicas } \\
\text { do Projeto }\end{array}$ & $\begin{array}{l}\text { PB_INFORMAÇOZES_BASICAS_DO_P } \\
\text { ROJETO 840132.pdf }\end{array}$ & $\begin{array}{c}07 / 05 / 2017 \\
11: 02: 38\end{array}$ & & Aceito \\
\hline $\begin{array}{l}\text { Projeto Detalhado / } \\
\text { Brochura } \\
\text { Investigador }\end{array}$ & $\begin{array}{l}\text { Pereira_ProjetoDetalhado_Brochura_Pla } \\
\text { taformaBrasil_versao2.doc }\end{array}$ & $\begin{array}{c}07 / 05 / 2017 \\
11: 00: 43\end{array}$ & $\begin{array}{l}\text { KARUZA MARIA } \\
\text { ALVES PEREIRA }\end{array}$ & Aceito \\
\hline $\begin{array}{l}\text { TCLE / Termos de } \\
\text { Assentimento / } \\
\text { Justificativa de } \\
\text { Ausência }\end{array}$ & $\begin{array}{l}\text { Justificativa_Ausencia_TCLE_Versao2.p } \\
\text { df }\end{array}$ & $\begin{array}{c}06 / 05 / 2017 \\
18: 33: 05\end{array}$ & $\begin{array}{l}\text { KARUZA MARIA } \\
\text { ALVES PEREIRA }\end{array}$ & Aceito \\
\hline $\begin{array}{l}\text { Declaração de } \\
\text { Instituição e } \\
\text { Infraestrutura }\end{array}$ & $\begin{array}{l}\text { Autorizacao_institucional_Lab_Patologia } \\
\text {.PDF }\end{array}$ & $\begin{array}{c}29 / 04 / 2017 \\
17: 01: 48\end{array}$ & $\begin{array}{l}\text { KARUZA MARIA } \\
\text { ALVES PEREIRA }\end{array}$ & Aceito \\
\hline Folha de Rosto & FOLHA_DE_ROSTO_Karuza.pdf & $\begin{array}{c}13 / 12 / 2016 \\
09: 23: 20\end{array}$ & $\begin{array}{l}\text { KARUZA MARIA } \\
\text { ALVES PEREIRA }\end{array}$ & Aceito \\
\hline Outros & $\begin{array}{l}\begin{array}{l}\text { TERMO_UTILIZACAO_DOS_DADOS.p } \\
\text { df }\end{array} \\
\end{array}$ & $\begin{array}{c}10 / 12 / 2016 \\
20: 33: 39\end{array}$ & $\begin{array}{l}\text { KARUZA MARIA } \\
\text { ALVES PEREIRA }\end{array}$ & Aceito \\
\hline Outros & TERMO_DE_FIEL_DEPOSITARIO.pdf & $\begin{array}{c}10 / 12 / 2016 \\
20: 15: 01\end{array}$ & $\begin{array}{l}\text { KARUZA MARIA } \\
\text { ALVES PEREIRA }\end{array}$ & Aceito \\
\hline Outros & Carta_de_solicitacao_CEP.pdf & $\begin{array}{c}10 / 12 / 2016 \\
20: 12: 30\end{array}$ & $\begin{array}{l}\text { KARUZA MARIA } \\
\text { ALVES PEREIRA }\end{array}$ & Aceito \\
\hline Orçamento & ORCAMENTO_PART_2.pdf & $\begin{array}{l}10 / 12 / 2016 \\
20: 05: 06\end{array}$ & $\begin{array}{l}\text { KARUZA MARIA } \\
\text { ALVES PEREIRA }\end{array}$ & Aceito \\
\hline Orçamento & ORCAMENTO_PART_1.pdf & $\begin{array}{l}10 / 12 / 2016 \\
20: 04: 44\end{array}$ & $\begin{array}{l}\text { KARUZA MARIA } \\
\text { ALVES PEREIRA }\end{array}$ & Aceito \\
\hline \begin{tabular}{|l|} 
Declaração de \\
Instituição e \\
Infraestrutura \\
\end{tabular} & AUTORIZACAO_INSTITUCIONAL.pdf & $\begin{array}{c}10 / 12 / 2016 \\
20: 03: 57\end{array}$ & $\begin{array}{l}\text { KARUZA MARIA } \\
\text { ALVES PEREIRA }\end{array}$ & Aceito \\
\hline $\begin{array}{l}\text { Declaração de } \\
\text { Pesquisadores }\end{array}$ & CONCORDANCIA_THALYTA.pdf & $\begin{array}{c}10 / 12 / 2016 \\
20: 02: 27\end{array}$ & $\begin{array}{l}\text { KARUZA MARIA } \\
\text { ALVES PEREIRA }\end{array}$ & Aceito \\
\hline \begin{tabular}{|l|} 
Declaração de \\
Pesquisadores
\end{tabular} & CONCORDANCIA_FILIPE.pdf & $\begin{array}{c}10 / 12 / 2016 \\
20: 02: 01\end{array}$ & $\begin{array}{l}\text { KARUZA MARIA } \\
\text { ALVES PEREIRA }\end{array}$ & Aceito \\
\hline \begin{tabular}{|l|} 
Declaração de \\
Pesquisadores
\end{tabular} & CONCORDANCIA_MARIO.pdf & $\begin{array}{c}10 / 12 / 2016 \\
20: 01: 33\end{array}$ & $\begin{array}{l}\text { KARUZA MARIA } \\
\text { ALVES PEREIRA }\end{array}$ & Aceito \\
\hline
\end{tabular}

Endereço: Rua Cel. Nunes de Melo, 1000

Bairro: Rodolfo Teofilo

UF: CE Municipio: FORTALEZA

Telefone: (85)3366-8344
CEP: $60.430-275$

E-mail: comepe@ufc.br 


\section{ANEXO C - NORMAS DE PUBLICAÇÃO DO PERIÓDICO INTERNATIONAL ORAL SURGERY, ORAL MEDICINE, ORAL PATHOLOGY AND ORAL RADIOLOGY}

\section{ORAL SURGERY, ORAL MEDICINE, ORAL PATHOLOGY AND ORAL RADIOLOGY}

The Official Publication for the American College of Oral and Maxillofacial Surgery, American Academy of Oral and Maxillofacial Radiology, American Academy of Oral Medicine, and the American Academy of Oral and Maxillofacial Pathology

\section{Section Scope Statements}

The Oral and Maxillofacial Surgery Section aims to publish an extensive range of original articles that advances patient care through enhanced understanding of diagnosis, surgical and adjunctive treatment of diseases, and injuries and defects involving both the functional and esthetic aspects of the hard and soft tissues of the oral and maxillofacial regions. The section also seeks research regarding both the basic science of and management of persons with oral and maxillofacial conditions. Articles presenting ethical, original, well-documented, and reproducible research are given preference.

The Oral Medicine Section aims to publish a broad range of original articles that help clinicians understand more thoroughly the pathobiology, etiology, diagnosis, prevention, and management of oral conditions related to underlying medical conditions, including diseases of the head, neck, and oral mucosal structures, orofacial pain conditions, salivary gland disorders, and taste disorders. The section also seeks research regarding the dental management of persons with medical problems and/or complicated medical conditions. The published findings must contribute substantively to the body of oral medicine literature and should lead to improved clinical decision-making and enhanced care of medically-related disorders or conditions affecting the oral and maxillofacial region. Articles presenting original, well-documented, and reproducible research are preferred.

The Oral and Maxillofacial Pathology Section encourages the submission of original articles of high scientific quality that investigate the pathogenesis, diagnosis, and management of diseases affecting the oral and maxillofacial region. Submitted manuscripts may summarize findings from clinical, translational, or basic research in the broad field of oral and maxillofacial pathology but must contribute substantively to the body of knowledge in this field and should be of obvious clinical and/ or diagnostic significance to the practicing oral and maxillofacial pathologist. Areas of focus may include the investigation of disease pathogenesis, the diagnosis of disease using microscopic, clinical, radiographic, biochemical, molecular, or other methods as well as the natural history and management of patients with various conditions of the head, neck, and oral mucosal structures. Diagnostic accuracy studies should conform to the principles of the STARD document http://www.stard-statement.org. Articles presenting novel and reproducible research that introduce new knowledge and observations are especially encouraged. This section also welcomes the submission of topical review papers on relevant subjects.

The Oral and Maxillofacial Radiology Section publishes original peer-reviewed contributions to the advancement of diagnostic clinical oral and maxillofacial radiology and 
related imaging sciences. The section considers original clinical and experimental research papers, technological developments, extensive systematic reviews of the literature, comprehensive pictorial reviews, special reports, and invited papers on subjects that will appeal to clinicians involved in the diagnostic imaging of hard and soft tissue maxillofacial pathology, selection criteria, computer-assisted diagnosis, craniofacial analysis, imageguided surgical navigation, image processing, dosimetry, radiation physics, biology, and safety. The section also seeks extensive case series representing various expressions of particular conditions, descriptions of innovative imaging technique applications to these series, and description of novel imaging features to assist imaging specialists develop clinical protocols and interpretive knowledge based on multiple observations. Only papers contributing substantively to the body of knowledge in oral and maxillofacial imaging and performed with scientific rigor will be considered. These papers should assist clinicians in developing evidence-based practice and provide improved clinical decision- making regarding the performance of specific techniques and interpretation of resulting images affecting the oral and maxillofacial region. Diagnostic accuracy studies should conform to the principles of the STARD document http://www.stard-statement.org.

Types of Papers Original Research Article. Reports of original research (preclinical, clinical, or translational) that are well-documented, novel, and significant. Original research manuscripts will be organized into six parts: (1) Abstract; (2) Introduction; (3) Materials and Methods; (4) Results; (5) Discussion; (6) References. Review article. Manuscripts that review the current status of a given topic, diagnosis, or treatment. These manuscripts should not be an exhaustive review of the literature but rather should be a review of contemporary thought with respect to the topic. Systematic reviews and meta-analyses manuscripts should follow PRISMA (http://www.prisma-statement.org) and the Institute of Medicines' guidelines (http://www.iom.edu/Reports/2011/Finding-What-Works inHealthCareStandards) forSystematic-Reviews/ Clinicopathologic Conference (CPC).

Manuscripts that document interesting, challenging, or unusual cases that present unexpected or interesting diagnostic challenges. The presentation should simulate clinical work-up, including the formulation of a detailed and well thought out differential diagnosis. The complete diagnostic evaluation, management, and follow-up must be included. CPC articles must be organized into six parts: (1) Title: Provide a descriptive clinical title that does not reveal the final diagnosis. (2) Clinical presentation: Describe the clinical and imaging characteristics of the lesion. Use clinical photographs and radiographs as appropriate. (3) Differential diagnosis: List and discuss lesions to be considered as reasonable diagnostic possibilities. The authors are reminded that the most important part of the CPC manuscript is the clinical differential diagnosis, where the authors guide the readership through their own diagnostic thought process. This will require the formulation of a list of the most probable diagnostic possibilities (ideally at least 5-6 entities) based on the clinical presentation, medical history, and/or radiographic studies. (4) Diagnosis: Histopathologic findings illustrated with appropriate photomicrographs. (5) Management: Describe the treatment of the patient and response to treatment. (6) Discussion: Concentrate on the most interesting aspect(s) of the case. No abstract is needed for CPC manuscripts. Limit the number of references to no more than25. Medical Management and Pharmacology Update (MMPU). This section is intended to provide concise, current reviews of medical problems and how they relate to dentistry. Manuscripts should include a good review of the 
clinical aspects of the disease, stressing the impact of the disease on the dental management and dental treatment of the patient. Emphasis should be placed on new developments, new research, or new approaches to therapy or management. Manuscripts should not be an exhaustive review of the literature but rather a review of contemporary thought with respect to the topic. Likewise, the bibliography need not be all inclusive but rather should include only seminal, contemporary references deemed by the author to be most pertinent. The desired format for manuscripts submitted for the MMPU section includes: (1) abstract; (2) topic introduction/overview; (3) epidemiology/demographics; (4) etiology and pathogenesis; (5) clinical presentation/physical findings; (6) diagnosis (laboratory tests, diagnostic imaging, etc.); (7) medical management and treatment; (8) complications; (9) prognosis; oral manifestations/dental implications and significance; and (10) dental management (of patients with the disease). Manuscripts should not exceed 12 pages in 12-point, doublespaced Times New Roman (tables and figures count toward the 12-page limit). Pharmacology Update is a component of the MMPU section that offers the reader the 67 opportunity to obtain concise information regarding drugs used in the practice of medicine, clinical dentistry, and dental specialties. Manuscripts should present clearly and concisely the background information regarding the disease or condition that is managed, the indications, rationale for and approved uses of the specific drugs or class of drugs, the advantages and benefits of the drug or drug class over previous drugs, mechanism of action, criteria for selection, usual dosage, pharmacokinetics, adverse effects, drug interactions, and oral health and dental management considerations. Emphasis should be placed on new developments, effectiveness in clinical trials, therapeutic outcomes, and safety. Manuscripts should reflect contemporary thought with respect to the topic. Use of figures to illustrate the mechanism of action and tables to present therapeutic outcomes, drug interactions, and adverse effects are encouraged. Manuscripts should utilize the MMPU categories for formatting the paper. Text should not exceed 3,000 words. Font should be 12-point, doublespaced Times New Roman. A maximum of 50 references is recommended. Case Reports. These types of publications often add little to the scientific knowledge base. However, excellent case reports may be published as online only papers if they meet certain criteria, such as: (1) rare or unusual lesions/conditions that need documentation, (2) welldocumented cases showing unusual or "atypical" clinical or microscopic features or behavior, or (3) cases showing good long- term follow-up information, particularly in areas in which good statistics on results of treatment are needed. A case report should either present unique features of the condition or lesion, novel treatment regimens, or provide the basis for a new plausible medical theory about the pathogenesis of a particular disease or condition so clinicians can provide better care regarding patients with chronic and painful conditions relevant to medical disorders and/or medical therapy. General inquiries and communications regarding editorial management should be addressed to Alice $\mathrm{M}$. Landwehr, Managing Editor: tripleOjournal@gmail.com. General correspondence to the Editor-in-Chief, Mark W. Lingen, DDS, PhD: Mark.Lingen@uchospitals.edu Publisherspecific inquiries should be addressed to: Jane Ryley, Elsevier Inc., 3251 Riverport Lane, Maryland Heights, MO 63043; e-mail: J.Ryley@Elsevier.com. Issue Manager, Jill Shepherd. Telephone: (352) 483-8113; fax: (352) 483-3417; e-mail: J.Shepherd@Elsevier.com. 


\section{BEFORE YOU BEGIN}

Ethics in publishing Please see our information pages on Ethics in publishing and Ethical guidelines for journal publication.

Declaration of interest All authors must disclose any financial and personal relationships with other people or organizations that could inappropriately influence (bias) their work. Examples of potential conflicts of interest include employment, consultancies, stock ownership, honoraria, paid expert testimony, patent applications/ registrations, and grants or other funding. If there are no conflicts of interest then please statethis: 'Conflicts of interest: none'. More information.

Submission declaration Submission of an article implies that the work described has not been published previously (except in the form of an abstract or as part of a published lecture or academic thesis or as an electronic preprint, see 'Multiple, redundant or concurrent publication' section of our ethics policy for more information), that it is not under consideration for publication elsewhere, that its publication is approved by all authors and tacitly or explicitly by the responsible authorities where the work was carried out, and that, if accepted, it will not be published elsewhere including electronically in the same form, in English or in any other language, without the written consent of the copyright-holder. If there is any overlap between the submission and any other material, published or submitted, detail the nature of and reason for the overlap for the editors' assessment. Although poster presentations and abstracts are not considered duplicate publication, they should be stated on the title page. Further information about Elsevier's standards for publication ethics is available at http://www.elsevier.com/publishingethics.

Authorship All authors should have made substantial contributions to all of the following: (1) the conception and design of the study, or acquisition of data, or analysis and interpretation of data, (2) drafting the article or revising it critically for important intellectual content, (3) final approval of the version to be submitted. All authors must have seen and approved the submission of the manuscript and be willing to take responsibility for the entire manuscript. All persons listed as authors must meet the criteria for authorship according to the "Uniform Requirements for Manuscripts Submitted to Biomedical Journals: Writing and Editing for Biomedical Publication" available at http://www.icmje.org. All persons who are identified as authors must have made substantial contribution to the manuscript through significantly contributing to the conception, design, analysis or interpretation of data; drafting or significantly revising the manuscript; and providing final approval of the manuscript throughout all its iterations. All three of these conditions must be met by each author. No additional authors can be added after submission unless editors receive agreement from all authors and detailed information is supplied as to why the author list should be amended. Persons who contribute to the effort in supporting roles should not be included as authors; they should be acknowledged at the end of the paper (see Acknowledgments below).

Changes to authorship Authors are expected to consider carefully the list and order of authors before submitting their manuscript and provide the definitive list of authors at the time of the original submission. Any addition, deletion or rearrangement of author names in the authorship list should be made only before the manuscript has been accepted and only if 
approved by the journal Editor. To request such a change, the Editor must receive the following from the

corresponding author: (a) the reason for the change in author list and (b) written confirmation (e-mail, letter) from all authors that they agree with the addition, removal or rearrangement. In the case of addition or removal of authors, this includes confirmation from the author being added or removed. Only in exceptional circumstances will the Editor consider the addition, deletion or rearrangement of authors after the manuscript has been accepted. While the Editor considers the request, publication of the manuscript will be suspended. If the manuscript has already been published in an online issue, any requests approved by the Editor will result in a corrigendum.

Registration of clinical trials Registration in a public trials registry is a condition for publication of clinical trials in this journal in accordance with International Committee of Medical Journal Editors recommendations. Trials must register at or before the onset of patient enrolment. The clinical trial registration number should be included at the end of the abstract of the article. A clinical trial is defined as any research study that prospectively assigns human participants or groups of humans to one or more health-related interventions to evaluate the effects of health outcomes. Health-related interventions include any intervention used to modify a biomedical or health-related outcome (for example drugs, surgical procedures, devices, behavioural treatments, dietary interventions, and process-ofcare changes). Health outcomes include any biomedical or health-related measures obtained in patients or participants, including pharmacokinetic measures and adverse events. Purely observational studies (those in which the assignment of the medical intervention is not at the discretion of the investigator) will not require registration.

Clinical trial results In line with the position of the International Committee of Medical Journal Editors, the journal will not consider results posted in the same clinical trials registry in which primary registration resides to be prior publication if the results posted are presented in the form of a brief structured (less than 500 words) abstract or table. However, divulging results in other circumstances (e.g., investors' meetings) is discouraged and may jeopardise consideration of the manuscript. Authors should fully disclose all posting in registries of results of the same or closely related work.

Article transfer service This journal is part of our Article Transfer Service. This means that if the Editor feels your article is more suitable in one of our other participating journals, then you may be asked to consider transferring the article to one of those. If you agree, your article will be transferred automatically on your behalf with no need to reformat. Please note that your article will be reviewed again by the new journal. More information.

Copyright Upon acceptance of an article, authors will be asked to complete a 'Journal Publishing Agreement' (see more information on this). An e-mail will be sent to the corresponding author confirming receipt of the manuscript together with a 'Journal Publishing Agreement' form or a link to the online version of this agreement. Subscribers may reproduce tables of contents or prepare lists of articles including abstracts for internal circulation within their institutions. Permission of the Publisher is required for resale or distribution outside the institution and for all other derivative works, including compilations and translations. If excerpts from other copyrighted works are included, the author(s) must obtain written permission from the copyright owners and credit the source(s) in the article. 
Elsevier has preprinted forms for use by authors in these cases. For open access articles: Upon acceptance of an article, authors will be asked to complete an 'Exclusive License Agreement' (more information). Permitted third party reuse of open access articles is determined by the author's choice of user license.

Author rights As an author you (or your employer or institution) have certain rights to reuse your work. More information.

Elsevier supports responsible sharing Find out how you can share your research publishedin Elsevier journals.

Role of the funding source You are requested to identify who provided financial support for the conduct of the research and/or preparation of the article and to briefly describe the role of the sponsor(s), if any, in study design; in the collection, analysis and interpretation of data; in the writing of the report; and in the decision to submit the article for publication. If the funding source(s) had no such involvement then this should be stated.

Funding body agreements and policies Elsevier has established a number of agreements with funding bodies which allow authors to comply with their funder's open access policies. Some funding bodies will reimburse the author for the Open Access Publication Fee. Details of existing agreements are available online. After acceptance, open access papers will be published under a noncommercial license. For authors requiring a commercial CC BY license, you can apply after your manuscript is accepted for publication.

Creative Commons Attribution-NonCommercial-NoDerivs (CC BY-NC-ND) For noncommercial purposes, lets others distribute and copy the article, and to include in a collective work (such as an anthology), as long as they credit the author(s) and provided they do not alter or modify the article. The open access publication fee for this journal is USD 2000, excluding taxes. Learn more about Elsevier's pricing policy: https://www.elsevier.com/openaccesspricing.

Green open access Authors can share their research in a variety of different ways and Elsevier has a number of green open access options available. We recommend authors see our green open access page for further information. Authors can also self-archive their manuscripts immediately and enable public access from their institution's repository after an embargo period. This is the version that has been accepted for publication and which typically includes author-incorporated changes suggested during submission, peer review and in editor-author communications. Embargo period: For subscription articles, an appropriate amount of time is needed for journals to deliver value to subscribing customers before an article becomes freely available to the public. This is the embargo period and it begins from the date the article is formally published online in its final and fully citable form. Find out more. This journal has an embargo period of 12 months.

Language (usage and editing services) Please write your text in standard, grammatical English (American or British usage is accepted, but not a mixture of these). Authors who feel their English language manuscript may require editing to eliminate possible grammatical or spelling errors and to conform to correct scientific English may wish to use the English Language Editing service available from Elsevier's WebShop ( http://webshop.elsevier.com/languageediting/) or visit our customer support site ( http://support.elsevier.com) for more information. Such assistance does not guarantee 
acceptance but may enhance the review, improve the chance of acceptance, and reduce the time until publication if the article is accepted.

Informed consent and patient details Studies on patients or volunteers require ethics committee approval and informed consent, which should be documented in the paper. Appropriate consents, permissions and releases must be obtained where an author wishes to include case details or other personal information or images of patients and any other individuals in an Elsevier publication. Written consents must be retained by the author and copies of the consents or evidence that such consents have been obtained must be provided to Elsevier on request. For more information, please review the Elsevier Policy on the Use of Images or Personal Information of Patients or other Individuals. Unless you have written permission from the patient (or, where applicable, the next of kin), the personal details of any patient included in any part of the article and in any supplementary materials (including all illustrations and videos) must be removed before submission.

Submission Our online submission system guides you stepwise through the process of entering your article details and uploading your files. The system converts your article files to a single PDF file used in the peer-review process. Editable files (e.g., Word, LaTeX) are required to typeset your article for final publication. All correspondence, including notification of the Editor's decision and requests for revision, is sent by e-mail. Submit your article Please submit your article via http://ees.elsevier.com/tripleo.

\section{PREPARATION}

Use of word processing software It is important that the file be saved in the native format of the word processor used. The text should be in single-column format. Keep the layout of the text as simple as possible. Most formatting codes will be removed and replaced on processing the article. In particular, do not use the word processor's options to justify text or to hyphenate words. However, do use bold face, italics, subscripts, superscripts etc. When preparing tables, if you are using a table grid, use only one grid for each individual table and not a grid for each row. If no grid is used, use tabs, not spaces, to align columns. The electronic text should be prepared in a way very similar to that of conventional manuscripts (see also the Guide to Publishing with Elsevier). Note that source files of figures, tables and text graphics will be required whether or not you embed your figures in the text. See also the section on Electronic artwork. To avoid unnecessary errors you are strongly advised to use the 'spell-check' and 'grammarcheck' functions of your word processor. LaTeX You are recommended to use the Elsevier article class elsarticle.cls to prepare your manuscript and BibTeX to generate your bibliography. Our LaTeX site has detailed submission instructions, templates and other information.

\section{Article structure}

Essential Title Page Information The title page of the manuscript should include the title of the article, the full name of the author(s), academic degrees, positions, and institutional affiliations. The corresponding author's address, business and home telephone numbers, fax number, and e-mail address should be given. Disclosures must appear on the title page (see Disclosures).

- Title. Concise and informative. Titles are often used in information-retrieval systems. Avoid abbreviations and formulae where possible. 
Author names, academic degrees, positions, and institutional affiliations. Where the family name may be ambiguous (e.g., a double name), please indicate this clearly. Present the authors' affiliation addresses (where the actual work was done) below the names. Indicate all affiliations with a lower-case superscript letter immediately after the author's name and in front of the appropriate address. Provide the full postal address of each affiliation, including the country name and, if available, the e-mail address of each author. Corresponding author. Clearly indicate who will handle correspondence at all stages of refereeing and publication, also post-publication. Ensure that phone numbers (with country and area code) are provided in addition to the e-mail address and the complete postal address. Contact details must be kept up to date by the corresponding author. Present/permanent address. If an author has moved since the work described in the article was done, or was visiting at the time, a 'Present address' (or 'Permanent address') may be indicated as a footnote to that author's name. The address at which the author actually did the work must be retained as the main, affiliation address. Superscript Arabic numerals are used for suchfootnotes.

Disclosures must appear on the title page (see "Conflict of Interest" above). Include on the title page a word count for the abstract (if relevant to article type), a complete manuscript word count (to include body text and figure legends), number of references, number of figures/tables, and number of supplementary elements, if any.

Statement of Clinical Relevance For Original research, Review, and MMPU manuscripts, please provide a brief statement of no more than 40 words that succinctly summarizes the clinical relevance of the findings described in your manuscript. For example: "The risk of postoperative bleeding complications in patients in whom anticoagulation is continued for dental surgery is exceedingly small and is outweighed by the small risk of serious and sometimes fatal embolic events when anticoagulation is interrupted for dental surgery." (Wahl et al. 119(2) doi:10.1016/j.oooo.2014.10.011)

Abstract A structured abstract, limited to 200 words, must be used for data-based research articles. The structured abstract is to contain the following major headings: Objective(s); Study Design; Results; and Conclusion(s). The Objective(s) reflects the purpose of the study, that is, the hypothesis that is being tested. The Study Design should include the setting for the study, the subjects (number and type), the treatment or intervention, and the type of statistical analysis. The Results include the outcome of the study and statistical significance if appropriate. The Conclusion(s) states the significance of the results. For nondata-based submissions, the abstract should be an unstructured summary of less than 150 words. No abstract is needed for submissions to the CPC section. Subdivision - unnumbered sections Divide your article into the following clearly defined sections. Each subsection is given a brief heading. Each heading should appear on its own separate line. Subsections should be used as much as possible when cross-referencing text: refer to the subsection by heading as opposed to simply 'the text'.

Introduction State the problem being investigated, summarize the existing knowledge to place the problem in context, and describe the hypothesis and general experimental design. Avoid a detailed literature survey or a summary of the results. Materials and Methods As relevant, the Materials and Methods section should describe in adequate detail the experimental subjects, their important characteristics, and the methods, 
apparatus, and procedures used so that other researchers can reproduce the experiment. When the manuscript submitted reports on research in which humans are involved as experimental subjects directly or indirectly, the Materials and Methods section must indicate that the protocol was reviewed by the appropriate institutional review board (IRB), is in compliance with the Helsinki Declaration, and that each subject in the project signed a detailed informed consent form. Authors should verify compliance with the Health Insurance Portability and Accountability Act of 1996 (HIPAA) before submission. Provide sufficient detail to allow the work to be reproduced. Methods already published should be indicated by a reference; only relevant modifications should be described. Animals. Please indicate that protocols were reviewed by the appropriate institutional committee with respect to the humane care and treatment of animals used in the study. Results Results should be clear and concise and presented in a logical sequence. Tables and illustrations may be helpful in clarifying the findings and can reduce the length of the manuscript.

Discussion The Discussion states the significance of the results and limitations of the study. Authors should discuss their findings in the framework of previously published research. They should explain why their results support or contradict existing knowledge. If appropriate, the authors may suggest further research to follow up on their findings. Formatting of funding sources List funding sources in this standard way to facilitate compliance to funder's requirements: Funding: This work was supported by the National Institutes of Health [grant numbers xxxx, yyyy]; the Bill \& Melinda Gates Foundation, Seattle, WA [grant number zzzz]; and the United States Institutes of Peace [grant number aaaa]. It is not necessary to include detailed descriptions on the program or type of grants and awards. When funding is from a block grant or other resources available to a university, college, or other research institution, submit the name of the institute or organization that provided the funding. If no funding has been provided for the research, please include the following sentence: This research did not receive any specific grant from funding agencies in the public, commercial, or not-for-profit sectors.

Units Follow internationally accepted rules and conventions: use the international system of units (SI). If other units are mentioned, please give their equivalent in SI. Dental Nomenclature. Because of competing dental nomenclature systems, confusion can be eliminated by identifying teeth by their name, rather than a number or letter. Be consistent throughout the manuscript. In tables, use the Universal Numbering System to identify the teeth. For example, the maxillary right permanent lateral incisor is designated tooth 7 . The mandibular right deciduous second molar is designated tooth T. Identify the numbers/letters in the footnote to the table like any other abbreviations.

\section{Math formulae}

Present simple formulae in the line of normal text where possible and use the solidus instead of a horizontal line for small fractional terms, e.g., X/Y. In principle, variables are to be presented in italics. Powers of e are often more conveniently denoted by exp. Number consecutively any equations that have to be displayed separately from the text (if referred to explicitly in thetext).

Footnotes Footnotes should be used sparingly. Number them consecutively throughout the article. Many word processors can build footnotes into the text, and this feature may be used. 
Otherwise, please indicate the position of footnotes in the text and list the footnotes themselves separately at the end of the article. Do not include footnotes in the Reference list.

\section{Acknowledgments}

The names of persons who have contributed substantially to a manuscript but who do not fulfill the criteria for authorship, along with their conflicts of interest, funding sources, and industry relations, if relevant, are to be listed in the Acknowledgment section. This section should include individuals who provided any writing, editorial, statistical assistance, etc. Collate acknowledgments in a separate section at the end of the article before the references and do not, therefore, include them on the title page, as a footnote to the title or otherwise. Do not include statements of the authors' funding, conflicts, or other disclosures in the Acknowledgments; these must appear on the title page.

References

Citation in text References should be complete and reflect the current state of knowledge on the topic. Make sure all references have been verified and are cited consecutively in the text (not including tables) by superscript numbers. The reference list should be typed doublespaced on a separate page of the manuscript file and numbered in the same order as the reference citations appear in the text. Please ensure that every reference cited in the text is also present in the reference list (and vice versa). Any references cited in the abstract must be given in full. Unpublished results and personal communications are not to be cited in the reference list but are to be cited in parentheses at the appropriate place in the text. Citation of a reference as 'in press' implies that the item has been accepted for publication, and publication information must be updated if the manuscript is accepted. Reference links Increased discoverability of research and high quality peer review are ensured by online links to the sources cited. In order to allow us to create links to abstracting and indexing services, such as Scopus, CrossRef and PubMed, please ensure that data provided in the references are correct. Please note that incorrect surnames, journal/book titles, publication year and pagination may prevent link creation. When copying references, please be careful as they may already contain errors. Use of the DOI is encouraged. A DOI can be used to cite and link to electronic articles where an article is in-press and full citation details are not yet known, but the article is available online. A DOI is guaranteed never to change, so you can use it as a permanent link to any electronic article. An example of a citation using DOI for an article not yet in an issue is: VanDecar J.C., Russo R.M., James D.E., Ambeh W.B., Franke M. (2003). Aseismic continuation of the Lesser Antilles slab beneath northeastern Venezuela. Journal of Geophysical Research, http://dx.doi.org/10.1029/2001JB000884i. Please note the format of such citations should be in the same style as all other references in the paper.

Web references As a minimum, the full URL should be given and the date when the reference was last accessed. Any further information, if known (DOI, author names, dates, reference to a source publication, etc.), should also be given. Web references can be listed separately (e.g., after the reference list) under a different heading if desired, or can be included in the reference list.

\section{Reference style}

If accepted, the reference style used by the journal will be applied to the accepted article by Elsevier at the proof stage. Make sure the information in each reference is complete and 
correct. To see the format used by the journal, refer to a recent issue. Journal abbreviation source Journal names should be abbreviated according to the List of Title Word Abbreviations: http://www.issn.org/services/online-services/access-to-the-ltwa/. Mendeley Users of Mendeley Desktop can easily install the reference style for this journal by clicking the following link: http://open.mendeley.com/use-citation-style/oral-surgeryoral-medicine-oral-pathology-andoral-radiology When preparing your manuscript, you will then be able to select this style using the Mendeley plugins for Microsoft Word or LibreOffice.

Artwork Electronic artwork Illustrations should be numbered with Arabic numerals in the order of appearance in the text and accompanied by suitable legends (see Figure Captions). A reasonable number of halftone illustrations or line drawings will be reproduced at no cost to the author. At the editors' discretion, color illustrations may be published in grayscale with the color image available in the online edition of the Journal; elaborate tables and extra illustrations, if accepted, may also appear as supplementary material in the online edition only. Typewritten or freehand lettering on illustrations is not acceptable. All lettering must be done professionally, and letters should be in proportion to the drawings or photographs on which they appear. Figures must be submitted in electronic figure file format. For best reproduction, images should be submitted in .tif format. Figures in .jpg format may be acceptable if they meet minimum resolution guidelines. Images embedded in programs such as PowerPoint or Word will not be accepted. Photographic images must be submitted at 300 ppi (pixels per inch) with the following dimensions: Full page 5" wide (1,500 pixels wide) or half page 3" wide (900 pixels wide). Screen capture resolutions (typically $72 \mathrm{ppi}$ ) will not provide adequate reproduction quality. Line-art images (charts, graphs) must be submitted at 1200 ppi with the following dimensions: Full page 5" wide (6000 pixels wide) or half page 3" wide (3600 pixels wide). Avoid background gridlines and other formatting that do not convey information (e.g., superfluous use of 3-dimensional formatting, background shadings). All images should be cropped to show only the area of interest and the anatomy necessary to establish a regional frame of reference. Although multipart figures are not preferred, if they are used, label multipart figures with capital letters (e.g., A, B, C, etc); do not exceed nine parts to one figure. If images are to be combined in one figure, they should be the same height and magnification to facilitate reproduction. For advice on image enhancement and annotation refer to Corl FM, et al. A five-step approach to digital image manipulation for the radiologist. RadioGraphics 2002;22:981-992. For further information, please see http://www.elsevier.com/artwork. See also Permissions.

Color artwork If, together with your accepted article, you submit usable color figures then Elsevier will ensure, at no additional charge, that these figures will appear in color on the Web (e.g., ScienceDirect and other sites) in addition to color reproduction in print. For further information on the preparation of electronic artwork, please see http://www.elsevier.com/artworkinstructions. Please note: Because of technical complications that can arise by converting color figures to 'gray scale' (for the printed version should you not opt for color in print), please submit in addition usable black and white versions of all the color illustrations.

Illustration services Elsevier's WebShop offers Illustration Services to authors preparing to submit a manuscript but concerned about the quality of the images accompanying their article. Elsevier's expert illustrators can produce scientific, technical and medical-style 
images, as well as a full range of charts, tables and graphs. Image 'polishing' is also available, where our illustrators take your image(s) and improve them to a professional standard. Please visit the website to find out more.

Figure captions Each illustration must be accompanied by a legend. These should be typed double-spaced on a separate page. Keep text in the illustrations themselves to a minimum but explain all symbols and abbreviations used. If an illustration has been taken from published or copyrighted material, the legend must give full credit to the original source and accompanied by signed, written permission from the copyright holder (see Permissions below).

Artwork: General points Make sure you use uniform lettering and sizing of your original artwork. Embed the used fonts if the application provides that option. Aim to use the following fonts in your illustrations: Arial, Courier, Times New Roman, Symbol, or fonts that look similar. Number the illustrations according to their sequence in the text. Use a logical naming convention for your artwork files. Provide captions to illustrations to appear as a separate page in the manuscript file. Size the illustrations close to the desired dimensions of the printed version. Submit each illustration as a separate file. A detailed guide on electronic artwork is available on our website: http://www.elsevier.com/artworkinstructions

You are urged to visit this site; some excerpts from the detailed information are given here.

Formats Please 'Save as' or convert the images to one of the following formats (note the resolution requirements for line drawings, halftones, and line/halftone combinations given below): EPS (or PDF): Vector drawings, embed all used fonts. TIFF (or JPEG): Color or grayscale photographs (halftones), keep to a minimum of 300 ppi. TIFF (or JPEG): Bitmapped (pure black \& white pixels) line drawings, keep to a minimum of 1200 ppi. Please do not:

Supply files that are optimized for screen use (e.g., GIF, BMP, PICT, WPG); these typically have a low number of pixels and limited set of colors;

Supply files that are too low in resolution;

Submit graphics that are disproportionately large for the content.

Tables Number tables consecutively using Roman numerals in accordance with their appearance in the text. Each table should be submitted as a separate file. Tables should be self-explanatory and should supplement, not duplicate, the text. All table reference citations should be repeats of numbers assigned within the text, not initial citations. A concise title should be supplied for each table. All columns should carry concise headings describing the data therein. Type all footnotes immediately below the table and define abbreviations (see also Dental Nomenclature above). If a table or any data therein have been previously published, a footnote to the table must give full credit to the original source and accompanied by signed, written permission from the copyright holder (see Permissions below).

Supplementary Data To save print pages and/or shorten an article to a readable length while allowing for detailed information to be available to interested readers, authors are 
encouraged to provide information that is essential for the discussion of the results of the submission in the submission itself and utilize supporting information to describe experimental details and nonessential but useful information as Supplementary Material. If the manuscript is accepted for print publication, a reference to the online material will appear in the print version. Supplementary files offer the author additional possibilities to publish supporting applications, high- resolution images, background datasets, sound clips and more. Supplementary files supplied will be published online alongside the electronic version of your article in Elsevier Web products, including ScienceDirect: http://www.sciencedirect.com. In order to ensure that your submitted material is directly usable, please provide the data in one of our recommended file formats. Authors should submit the material in electronic format together with the article and supply a concise and descriptive caption for each file. For more detailed instructions please visit our artwork instruction pages at http://www.elsevier.com/artworkinstructions. Upload material, figures, and tables for online publication under the submission item "Supplementary Material" through the EES system. Be sure to change the description of the Supplementary Material to reflect the content; for example, Supplementary Detailed Methodology, Supplementary Figure Sx, Supplementary Table Sx. Please order material such as Figures and Supplemental Figures separately in order of the callouts/ first mentions in the text. For example: Figure 1, Figure 2; Supplemental Figure S1, Supplemental Figure S2, etc. In the text be sure that you add behind the reference to the supplemental material "(Supplemental Table Sx; available at [URL/link*])." * To be provided by the production department.

\section{Data references}

This journal encourages you to cite underlying or relevant datasets in your manuscript by citing them in your text and including a data reference in your Reference List. Data references should include the following elements: author name(s), dataset title, data repository, version (where available), year, and global persistent identifier. Add [dataset] immediately before the reference so we can properly identify it as a data reference. The [dataset] identifier will not appear in your published article.

\section{Reference Style}

Text: Indicate references by superscript number(s) in the text. The actual authors can be referred to, but the reference number(s) must always be given. Example: '......as demonstrated.3,6 Barnaby and Jones8 obtained a different result ....' List: Number the references in the list in the order in which they appear in the text. Examples: Reference to a journal publication: J. van der Geer, J.A.J. Hanraads, R.A. Lupton, The art of writing a scientific article, J. Sci. Commun. 163 (2010) 51-59. Reference to a book: W. Strunk Jr., E.B. White, The Elements of Style, fourth ed., Longman, New York, 2000. Reference to a chapter in an edited book: G.R. Mettam, L.B. Adams, How to prepare an electronic version of your article, in: B.S. Jones, R.Z. Smith (Eds.), Introduction to the Electronic Age, E-Publishing Inc., New York, 2009, pp. 281-304. [dataset] 5. Oguro, M, Imahiro, S, Saito, S, Nakashizuka, T. Mortality data for Japanese oak wilt disease and surrounding forest compositions, Mendeley Data, v1; 2015. http://dx.doi.org/10.17632/ xwj98nb39r.1. 


\section{Imaging Data DICOM Viewer}

If your paper contains images generated from DICOM data, you may receive an invitation from the Section editor(s) after submission inviting you to complement your online article by providing volumetric radiological data of a case, a specific example, or multiple datasets in DICOM format. Readers will be able to interact, adjust, display, and view the DICOM data using an interactive viewer embedded within your article. Specifically, the viewer will enable users to explore the DICOM data as 2D orthogonal MPR series, 3D volume rendering and 3D MIP. Specific enhancements include zoom, rotate and pan 3D reconstructions, section through the volume, and change opacity and threshold level. Each DICOM dataset will have to be zipped in a folder and uploaded to the online submission system via the "DICOM dataset" submission category. The recommended size of a single uncompressed dataset is $200 \mathrm{MB}$ or less. Please provide a short informative description for each dataset by filling in the 'Description' field when uploading each ZIP file. Note: All datasets will be available for download from the online article on ScienceDirect, so please ensure that all DICOM files are anonymized before submission. For more information see: http://www.elsevier.com/about/content innovation/radiologicaldata.

\section{Video}

Elsevier accepts video material and animation sequences to support and enhance your scientific research. Authors who have video or animation files that they wish to submit with their article are strongly encouraged to include links to these within the body of the article. This can be done in the same way as a figure or table by referring to the video or animation content and noting in the body text where it should be placed. All submitted files should be properly labeled so that they directly relate to the video file's content. In order to ensure that your video or animation material is directly usable, please provide the files in one of our recommended file formats with a preferred maximum size of $150 \mathrm{MB}$. Video and animation files supplied will be published online in the electronic version of your article in Elsevier Web products, including ScienceDirect. Please supply 'stills' with your files: you can choose any frame from the video or animation or make a separate image. These will be used instead of standard icons and will personalize the link to your video data. For more detailed instructions please visit our video instruction pages. Note: since video and animation cannot be embedded in the print version of the journal, please provide text for both the electronic and the print version for the portions of the article that refer to this content.

\section{Permissions}

Upload written permissions from the copyright holder to republish previously published material. Authors are responsible for obtaining and uploading any needed permissions and for clearly and completely identifying any overlapping material and/or quoted or paraphrased passages with proper attribution in the text to avoid plagiarism (including selfplagiarism). The Permissions FAQ for Authors is available at http://www.elsevier.com/authors/permission-seeking-guidelines-for-elsevier-authors. For assistance, please contact Elsevier's Permissions Helpdesk: +1-800-523-4069 x 3808; +1215-239-3805; permissionshelpdesk@elsevier.com Written, signed permission(s) from the patient or legal guardian is/are required for publication of recognizable photographs. Clearly state in your cover letter that patient consent has been obtained and has been uploaded under 
"Permission/s." If it is impossible to obtain a consent form, the image(s) must be removed or sufficiently cropped to the area of interest only or otherwise changed so the patient cannot be recognized. However, blurring or placing bars over the eyes is no longer acceptable to eliminate the need for a signed consent form. The restrictions for photos have become very strict. For more information, refer to http://www.elsevier.com/about/companyinformation/policies/patient-consent.

Letters to the Editor Letters to the Editor should be a succinct comment pertaining to a paper(s) published in the Journal within the past year or to related topics. Provide a unique title for the Letter on the title page with complete contact information for the author(s). Double-space the text of the Letter. References, including reference to the pertinent article(s) in the Journal, should conform to style for manuscripts (see References). If accepted, the author(s) of the pertinent article(s) may be contacted to prepare a response to the comment. Announcements Announcements must be received by the Editorial Office at least 10 weeks before the desired month of publication. Items published at no charge include those received from a sponsoring society of the Journal; courses and conferences sponsored by state, regional, or national dental organizations; and programs for the dental profession sponsored by government agencies. All other announcements selected for publication by the Editor carry a charge of $\$ 60$ US, and the fee must accompany the request to publish. ARTICLE ENRICHMENTS

AudioSlides The journal encourages authors to create an AudioSlides presentation with their published article. AudioSlides are brief, webinar-style presentations that are shown next to the online article on ScienceDirect. This gives authors the opportunity to summarize their research in their own words and to help readers understand what the paper is about. More information 78 and examples are available. Authors of this journal will automatically receive an invitation email to create an AudioSlides presentation after acceptance of their paper.

\section{$3 D$ radiological data}

You can enrich your online article by providing 3D radiological data in DICOM format. Radiological data will be visualized for readers using the interactive viewer embedded within your article, and will enable them to: browse through available radiological datasets; explore radiological data as 2D series, 2D orthogonal MPR, 3D volume rendering and 3D MIP; zoom, rotate and pan 3D reconstructions; cut through the volume; change opacity and threshold level; and download the data. Multiple datasets can be submitted. Each dataset will have to be zipped and uploaded to the online submission system via the '3D radiological data' submission category. The recommended size of a single uncompressed dataset is 200 $\mathrm{MB}$ or less. Please provide a short informative description for each dataset by filling in the 'Description' field when uploading each ZIP file. Note: all datasets will be available for download from the online article on ScienceDirect. So please ensure that all DICOM files are anonymized prior to submission. More information.

Virtual Microscope The journal encourages authors to supplement in-article microscopic images with corresponding high resolution versions for use with the Virtual Microscope viewer. The Virtual Microscope is a web based viewer that enables users to view microscopic images at the highest level of detail and provides features such as zoom and pan. This feature for the first time gives authors the opportunity to share true high resolution microscopic images with their readers. More information and examples. Authors of this 
journal will receive an invitation e-mail to create microscope images for use with the Virtual Microscope when their manuscript is first reviewed. If you opt to use the feature, please contact virtualmicroscope@elsevier.com for instructions on how to prepare and upload the required high resolution images.

Submission Checklist The following list will be useful during the final checking of an article prior to sending it to the journal for review. Please consult this Guide for Authors for further details of anyitem.

Ensure that the following items are present: Letter of submission, to include disclosure of any previous publications or submissions with any overlapping information Statement of clinical relevance (uploaded separately) Title page Title of article Full names(s), academic degree(s), affiliation(s) and titles of author(s) Author to whom correspondence, proof, and reprint requests are to be sent, including address and business and home telephone numbers, fax number, and e-mail address Any conflict of interest statement(s), disclosure(s), and/or financial support information, including donations Word count for the abstract (if relevant to article type), a complete manuscript word count (to include body text and figure legends), number of references, and number of figures/tables Structured abstract (double-spaced as part of manuscript file), as relevant to article type Article proper (double-spaced) Statement of IRB review and compliance with Helsinki Declaration (stated in Methods section of manuscript, as relevant) References (double-spaced on a separate page of the manuscript file) Figure legends (double-spaced, on a separate page of the manuscript file) Tables (double-spaced, uploaded separately as word processing [eg, .doc] files) Illustrations, properly formatted (uploaded as separate files) Video/computer graphics, properly formatted (uploaded as separate files) Signed permission to reproduce any previously published material, in all forms and media (scanned in as a file and uploaded as Permission) Signed permission to publish photographs of identifiable persons from the individual or legal guardian specifying permission in all forms and media (scanned in as a file and uploaded as Permission) For any further information please visit our customer support site at 79 http://support.elsevier.com

\section{AFTER ACCEPTANCE}

Proofs One set of page proofs (as PDF files) will be sent by e-mail to the corresponding author (if we do not have an e-mail address then paper proofs will be sent by post) or, a link will be provided in the e-mail so that authors can download the files themselves. Elsevier now provides authors with PDF proofs which can be annotated; for this you will need to download the free Adobe Reader, version 9 (or higher). Instructions on how to annotate PDF files will accompany the proofs (also givenonline). The exact system requirements are given at the Adobe site. If you do not wish to use the PDF annotations function, you may list the corrections (including replies to the Query Form) and return them to Elsevier in an e-mail. Please list your corrections quoting line number. If, for any reason, this is not possible, then mark the corrections and any other comments (including replies to the Query Form) on a printout of your proof and scan the pages and return via e- mail. Please use this proof only for checking the typesetting, editing, completeness and correctness of the text, tables and figures. Significant changes to the article as accepted for publication will only be considered at this stage with permission from the Editor. We will do everything possible to get your article published quickly and accurately. It is important to ensure that all corrections are sent 
back to us in one communication: please check carefully before replying, as inclusion of any subsequent corrections cannot be guaranteed. Proofreading is solely yourresponsibility. AUTHOR INQUIRIES

Visit the Elsevier Support Center to find the answers you need. Here you will find everything from Frequently Asked Questions to ways to get in touch. You can also check the status of your submitted article or find out when your accepted article will be published. 